\title{
MIPAS temperature from the stratosphere to the lower thermosphere: Comparison of vM21 with ACE-FTS, MLS, OSIRIS, SABER, SOFIE and lidar measurements
}

\author{
M. García-Comas ${ }^{1}$, B. Funke ${ }^{1}$, A. Gardini ${ }^{1}$, M. López-Puertas ${ }^{1}$, A. Jurado-Navarro ${ }^{1}$, T. von Clarmann ${ }^{2}$, G. Stiller ${ }^{2}$, \\ M. Kiefer ${ }^{2}$, C. D. Boone ${ }^{3}$, T. Leblanc ${ }^{4}$, B. T. Marshall ${ }^{5}$, M. J. Schwartz ${ }^{6}$, and P. E. Sheese \\ ${ }^{1}$ Instituto de Astrofísica de Andalucía-CSIC, Granada, Spain \\ ${ }^{2}$ Karlsruhe Institut für Technologie, Institut für Meteorologie und Klimaforschung, Karlsruhe, Germany \\ ${ }^{3}$ Univ. of Waterloo, Waterloo, Ontario, Canada \\ ${ }^{4}$ California Institute of Technology, Jet Propulsion Laboratory, Wrightwood, CA, USA \\ ${ }^{5}$ GATS Inc., Newport News, VA, USA \\ ${ }^{6}$ Jet Propulsion Laboratory, Pasadena, CA, USA \\ ${ }^{7}$ University of Toronto, Toronto, Ontario, Canada \\ Correspondence to: M. García-Comas (maya@iaa.es)
}

Received: 21 May 2014 - Published in Atmos. Meas. Tech. Discuss.: 4 July 2014

Revised: 10 September 2014 - Accepted: 29 September 2014 - Published: 6 November 2014

\begin{abstract}
We present vM21 MIPAS temperatures from the lower stratosphere to the lower thermosphere, which cover all optimized resolution measurements performed by MIPAS in the middle-atmosphere, upper-atmosphere and noctilucentcloud modes during its lifetime, i.e., from January 2005 to April 2012. The main upgrades with respect to the previous version of MIPAS temperatures (vM11) are the update of the spectroscopic database, the use of a different climatology of atomic oxygen and carbon dioxide, and the improvement in important technical aspects of the retrieval setup (temperature gradient along the line of sight and offset regularizations, apodization accuracy). Additionally, an updated version of ESA-calibrated L1b spectra (5.02/5.06) is used. The vM21 temperatures correct the main systematic errors of the previous version because they provide on average a $1-2 \mathrm{~K}$ warmer stratopause and middle mesosphere, and a $6-10 \mathrm{~K}$ colder mesopause (except in high-latitude summers) and lower thermosphere. These lead to a remarkable improvement in MIPAS comparisons with ACE-FTS, MLS, OSIRIS, SABER, SOFIE and the two Rayleigh lidars at Mauna Loa and Table Mountain, which, with a few specific exceptions, typically exhibit differences smaller than $1 \mathrm{~K}$ below $50 \mathrm{~km}$ and than $2 \mathrm{~K}$ at $50-80 \mathrm{~km}$ in spring, autumn and winter at all latitudes, and summer at low to midlatitudes. Differences in the high-latitude summers are typically smaller than $1 \mathrm{~K}$ below
\end{abstract}

$50 \mathrm{~km}$, smaller than $2 \mathrm{~K}$ at $50-65 \mathrm{~km}$ and $5 \mathrm{~K}$ at $65-80 \mathrm{~km}$. Differences between MIPAS and the other instruments in the mid-mesosphere are generally negative. MIPAS mesopause is within $4 \mathrm{~K}$ of the other instruments measurements, except in the high-latitude summers, when it is within 5-10 K, being warmer there than SABER, MLS and OSIRIS and colder than ACE-FTS and SOFIE. The agreement in the lower thermosphere is typically better than $5 \mathrm{~K}$, except for high latitudes during spring and summer, when MIPAS usually exhibits larger vertical gradients.

\section{Introduction}

The Michelson Interferometer for Passive Atmospheric Sounding (MIPAS) (Fischer et al., 2008) onboard Envisat (Environmental Satellite) globally measured the day and night limb emission from atmospheric constituents from July 2002 to April 2012, when contact to the satellite was lost. MIPAS spectra cover wavelengths from 4.3 to $15.6 \mu \mathrm{m}$ with a resolution of $0.035 \mathrm{~cm}^{-1}$ (unapodized, full resolution) from 2002 to 2004 and $0.0625 \mathrm{~cm}^{-1}$ (unapodized, reduced resolution) onwards. MIPAS was in a Sun-synchronous orbit, with ascending/descending nodes at 
10:00/22:00 LT. MIPAS almost continuously measured in its nominal (NOM) mode $(6-68 \mathrm{~km})$ but used special modes to expand its measurements to the mesosphere and lower thermosphere (MLT) during around ten 2-3 full-day campaigns in 2005 and 2006 and on a regular basis (every 10 days) starting in March 2007. These special modes of operation are the middle-atmosphere mode (MA; covering 18-102 km, in $3 \mathrm{~km}$ vertical steps), the upper-atmosphere mode (UA; covering $40-102 \mathrm{~km}$, in $3 \mathrm{~km}$ steps, and $102-170 \mathrm{~km}$, in $5 \mathrm{~km}$ steps) and the noctilucent-cloud mode (NLC; covering $39-102 \mathrm{~km}$, in $3 \mathrm{~km}$ steps except at $78-87 \mathrm{~km}$, where $1.5 \mathrm{~km}$ vertical steps were used; this mode was only used for 3-day campaigns in the solstices) (Oelhaf, 2008).

The MA-, NLC- and UA-mode measurements are currently used to derive kinetic temperature, ozone, water vapor, methane, carbon monoxide, nitric oxide, nitrous oxide, nitrogen dioxide and ice volume density in the MLT. The retrieval of temperature and line-of-sight vertical pointing information (TLOS) is the first one in this chain, since TLOS is needed for all other retrievals. Thus, assuring a highquality TLOS is essential. TLOS is retrieved from the $\mathrm{CO}_{2}$ atmospheric emission measured by MIPAS around $15 \mu \mathrm{m}$ up to the lower thermosphere, which, in contrast to the retrievals from measurements in the NOM mode (von Clarmann et al., 2003), needs the inclusion of a nonlocal thermodynamic equilibrium (non-LTE) model, since the atmospheric infrared emissions at those altitudes are generally affected by these effects (López-Puertas and Taylor, 2001). García-Comas et al. (2012) (GC2012 hereafter) documented the first release of temperatures in the MA, UA and NLC modes (vM11, where $M=5,6$ and 7 stand for MA, UA and NLC, respectively). Those versions included measurements from 2005 to 2009. GC2012 made a comprehensive description of the retrieval setup and the mechanisms considered in the non-LTE model, and compared the results with measurements from other instruments. The spectra provided by the European Space Agency (ESA) used to generate that TLOS version were version 4.61/4.62.

MIPAS L1b spectra in the version 4.61/4.62 are not available for measurements made after 2009, but the updated version 5.02/5.06 is provided from then on. Changes from the former version to the latter in engineering altitude and in radiance, due to a new calibration, nonlinearity corrections of the detectors and a better treatment of the forward/reverse problem are significant. That implies that a uniform MIPAS data set covering all MIPAS MA, UA and NLC temperature measurements using vM11 is not possible. Fortunately, the spectra version 5.02/5.06 L1b was released for all measurements made by MIPAS during its lifetime. These two facts motivated us to generate a new version of TLOS using 5.02/5.06 spectra. Since the comparisons of temperature with other instruments in GC2012 showed systematic differences, we also modified the retrieval setup with the aim of addressing their causes.
We present for the first time a complete MIPAS reducedresolution (January 2005-April 2012) MA/UA/NLC temperature data set in versions v521, v621 and v721 (vM21 hereafter). We describe the improvements introduced in these retrievals, their impact on MIPAS temperatures and the retrieved temperature fields in Sect. 2. In order to assess the quality of these new versions, we compare these temperatures with measurements from five satellite instruments and two lidars. A short summary of each of these instruments is presented in Sect. 3. Section 4 describes the results of the comparisons from 20 to $100 \mathrm{~km}$, including a discussion on the differential behavior in the different modes of observations and in the two hemispheres. Section 6 summarizes our findings.

\section{The temperature retrieval: improvements in vM21}

The retrieval of temperature, line-of-sight (LOS) altitude information and temperature horizontal (mainly latitudinal) gradients in versions vM21 is done from measurements of the $\mathrm{CO}_{2}$ atmospheric radiance at $15 \mu \mathrm{m}$ for each MIPAS single limb scan. The scheme of the setup follows that described in detail for vM11 by GC2012, which in turn is an extension of the retrieval in the MIPAS NOM mode (von Clarmann et al., 2003) with the GRANADA non-LTE model described in Funke et al. (2012). We note that vM21 uses the same microwindows as vM11 (see Table 1 in GC2012) and the same retrieval altitude grid $(1 \mathrm{~km}$ below $50 \mathrm{~km}$ and $2 \mathrm{~km}$ above; we note that the forward calculations are performed using the finer grid $(1 \mathrm{~km})$ up to $88 \mathrm{~km})$. The main upgrades introduced in the retrieval vM21 and their impact on the retrieved temperatures with respect to vM11 are as follows:

- MIPAS L1b spectra: VM21 retrievals use calibrated spectra as supplied by ESA in version 5.02/5.06 (Raspollini et al., 2010, and references therein). The effect on retrieved temperatures, compared to results using the previous 4.61/4.62 spectra, is smaller than $1-2 \mathrm{~K}$ below $90 \mathrm{~km}$ (when affected, that difference is generally positive) and temperature decreases above that altitude, exhibiting the maximum difference (in absolute value) at $95 \mathrm{~km}(-10 \mathrm{~K})$. That occurs at all latitudes and in all seasons except for the summer at latitudes higher than $70^{\circ}$. Under the latter conditions, the changes are more pronounced. The effect is there smaller than $1-2 \mathrm{~K}$ only below $75 \mathrm{~km}$, the temperature increases by $4 \mathrm{~K}$ around $75 \mathrm{~km}$ and at the mesopause, and it decreases above that altitude, with the maximum change at $95 \mathrm{~km}(-15 \mathrm{~K})$.

- Atomic oxygen climatology: the role of the atomic oxygen in MIPAS temperature retrievals is important at and above the mesopause. Atomic oxygen efficiently quenches the vibrationally excited $\mathrm{CO}_{2}$ molecules 
there, where it is more abundant, and thus it is needed to calculate the populations of the emitting $\mathrm{CO}_{2}\left(v_{2}\right)$ levels with the non-LTE model. Consequently, changes in the atomic oxygen concentration affect temperatures retrieved from measurements of atmospheric $15 \mu \mathrm{m}$ emissions.

The vM21 TLOS retrieval uses an atomic oxygen climatology from the WACCM model (Garcia et al., 2007) in its specified dynamics (SD) configuration. WACCM-SD (or WACCM4) constrains the meteorological fields in the troposphere and stratosphere with observations (Lamarque et al., 2012). The model is freerunning above. We recall that vM11 used atomic oxygen mixing ratios from the NRLMSISE-00 model (Picone et al., 2002). Differences between NRLMSISE-00 and WACCM-SD atomic oxygen depend on altitude, latitude and season, leading to corresponding dependencies in the retrieved temperature. The response of the retrieved temperature compensates for the changes in the modeled $\mathrm{CO}_{2}$ vibrational levels non-LTE populations induced by the change in the atomic oxygen abundance, which are described in García-Comas et al. (2008) for different atmospheric conditions. The changes in MIPAS temperatures are less than $1 \mathrm{~K}$ below $80 \mathrm{~km}$ at high latitudes $\left(>50^{\circ}\right)$ and below $95 \mathrm{~km}$ elsewhere. In the summer high latitudes, WACCM-SD atomic oxygen is 2-3 times larger than NRLMSISE-00 at the mesopause $(88 \mathrm{~km})$, leading to $5-6 \mathrm{~K}$ higher temperatures, and it is 4-5 times larger from 95 to $100 \mathrm{~km}$, leading to 10 to $20 \mathrm{~K}$ lower temperatures, respectively. WACCM atomic oxygen in the winter and equinox high latitudes is up to 3 times larger than NRLMSISE-00 at $85 \mathrm{~km}$, causing a decrease in temperature of only $1 \mathrm{~K}$ at that altitude, and slightly changes at $100 \mathrm{~km}$, producing an unnoticeable effect there. At low latitudes, WACCM-SD atomic oxygen is larger than NRLMSISE-00 above $95 \mathrm{~km}$ by a maximum factor of 1.5 , which decreases temperature by $3 \mathrm{~K}$ at $100 \mathrm{~km}$.

As mentioned above, the atomic oxygen from the WACCM-SD model significantly differs from that from the NRLMSISE-00 model. The response of the retrieved temperature to that change shows that special care should be taken when selecting the atomic oxygen for MIPAS temperature retrievals. In order to detect potential differences with the real atmospheric atomic oxygen, we have compared its WACCM-SD abundance with that measured by SABER. Mlynczak et al. (2013) describe the derivation of atomic oxygen concentration below about $95 \mathrm{~km}$ from SABER measurements with a 20-30\% uncertainty. Except for the polar summer, comparisons of SABER and WACCM-SD atomic oxygen show differences smaller than $20 \%$ around and above $90 \mathrm{~km}$. Differences around $85 \mathrm{~km}$ reach $50 \%$. In the polar summer, however, WACCM-SD atomic oxygen is 2 times larger than SABER's above $90 \mathrm{~km}$. Around the polar summer mesopause $(88 \mathrm{~km})$, that difference reaches a factor of 5 . In other words, the comparison with SABER suggests that an overestimation of WACCM-SD atomic oxygen may lead to overestimated polar summer mesopause temperatures. Additionally, it is worth noting that Kaufmann et al. (2014) show that SABER's atomic oxygen abundance in the mesopause region is around $30 \%$ larger than that measured by WINDII, OSIRIS and SCIAMACHY, although their comparisons are limited to latitudes lower than $\approx 60^{\circ}$, i.e., they do not comprise polar latitudes.

- Carbon dioxide climatology: MIPAS TLOS is derived from measurements of emission in carbon dioxide spectral lines using prior knowledge of $\mathrm{CO}_{2}$ abundance. Changes of that $\mathrm{CO}_{2}$ concentration influence the TLOS retrieval. The vM21 TLOS retrieval uses a carbon dioxide climatology from the WACCM-SD model. The WACCM-SD $\mathrm{CO}_{2}$ trend correction takes into account the observed emission growth. Previous vM11 used a trend-corrected 2000-2003 WACCM3 (free-running) composite monthly mean climatology. Retrieved temperature variations due to the change from WACCM3 to WACCM-SD $\mathrm{CO}_{2}$ are $-1 \mathrm{~K}$ at low and midlatitudes and $2-3 \mathrm{~K}$ in the winter high latitudes above $85 \mathrm{~km}, 2-6 \mathrm{~K}$ in the summer high latitudes above $90 \mathrm{~km}$, and smaller than $0.5 \mathrm{~K}$ elsewhere.

- Spectroscopic database: we now use spectroscopic and corresponding line mixing data from HITRAN 2008 (Rothman et al., 2009) instead of HITRAN 2004, used in vM11. Changes in retrieved temperature are small below $70 \mathrm{~km}$, in general, but there is a noteworthy $1 \mathrm{~K}$ increase around $50 \mathrm{~km}$ at all latitudes. Above $70 \mathrm{~km}$, the change oscillates with an amplitude of $1-2 \mathrm{~K}$ at all latitudes except in the polar summer, when the amplitude is $3 \mathrm{~K}$.

- Apodization accuracy: we changed the width of the integration window of the apodized instrument line shape function, which reduced channel border effects. The impact of the new apodization spectral window on retrieved temperature is negligible below $90 \mathrm{~km}$ except in the summer high latitudes $\left(>50^{\circ}\right)$ around $75-85 \mathrm{~km}$, where temperature increases up to $1-2 \mathrm{~K}$. Temperatures at all latitudes decrease above $90 \mathrm{~km}$ up to $2-3 \mathrm{~K}$ at $95 \mathrm{~km}$.

- Offset regularization: the radiance offset in each microwindow used is also determined in the MIPAS TLOS retrieval. López-Puertas et al. (2009) studied MIPAS integrated radiance around $12 \mu \mathrm{m}$ (same MIPAS channel as $15 \mu \mathrm{m}$ ) in the middle atmosphere for polar summer measurements and found a systematic radiance offset. After exploring the offset multiyear global mean in the 
microwindows at $15 \mu \mathrm{m}$ at varied atmospheric conditions, we now regularize the offset retrieval using an a priori of $3 \mathrm{nW}\left(\mathrm{cm}^{2} \mathrm{~cm}^{-1} \mathrm{sr}\right)^{-1}$. We note here that unregularized offset retrieval leads to problems during polar summer (crosstalk); hence a (weak) constraint is required to balance the weight from the temperature constraint (the temperature a priori being too high in polar summer). The retrieved temperature changes less than $1 \mathrm{~K}$ below $70 \mathrm{~km}$ due to this approach. Temperature decreases $2 \mathrm{~K}$ from 90 to $95 \mathrm{~km}$ at all latitudes except at those higher than $60^{\circ}$ during the summer, when it decreases $3 \mathrm{~K}$. This regularization slightly increases the number of non-converged scans but significantly decreases the chi square.

- Temperature horizontal gradient regularization: the consideration of temperature horizontal inhomogeneities along the line of sight is important in order to accurately retrieve atmospheric variables from MIPAS measurements in the troposphere and the stratosphere (Kiefer et al., 2010). Figure 1 shows the impact of the exclusion of temperature gradients along the line of sight on zonal mean MIPAS v521 retrieved temperature for 3 June 2010. The gradients used for these example calculations are those simultaneously retrieved in vM21 TLOS retrievals. When a horizontally homogeneous atmosphere is considered in the forward calculations, retrieved temperature below about $85 \mathrm{~km}$ is similar at tropical and mid latitudes. It also changes less than $1 \mathrm{~K}$ below $60 \mathrm{~km}$ at other latitudes, but, at $65-85 \mathrm{~km}$, temperature is under/overestimated by $2 \mathrm{~K}$ (depending on the altitude) at the Equator and underestimated by up to $2 \mathrm{~K}$ at the poles. The effect is larger at $85-100 \mathrm{~km}$ at all latitudes. The temperature is there underestimated by as much as $4 \mathrm{~K}$ in the polar winter, $10 \mathrm{~K}$ at midand low latitudes and $18 \mathrm{~K}$ in the polar summer. This example proves the need to consider temperature horizontal gradients in order to provide accurate MIPAS temperature retrievals up to the lower thermosphere.

Both MIPAS vM11 and vM21 retrievals account for horizontal temperature gradients, which are simultaneously retrieved in the TLOS retrieval. A profile of the horizontal temperature gradient along line of sight is directly retrieved from each individual MIPAS scan (see von Clarmann et al., 2009, for further details). Nevertheless, comparisons of the vM11 directly retrieved temperature horizontal gradients with the numerical gradients generated using the vM11 retrieved temperature fields showed inconsistencies in the mesosphere. An improved regularization scheme, with a weaker regularization above the stratopause, is used in vM21. Figure 2 shows the retrieved zonal mean horizontal temperature gradients averaged for 1 day of July MA measurements. These are now consistent (both in their latitudinal-vertical distribution and magnitude) with the gradi- ents derived from the retrieved temperature fields. This improvement affects the retrieved temperature. Temperature decreases by $1-2 \mathrm{~K}$ between 70 and $80 \mathrm{~km}$ for summer conditions and increases by $1-2 \mathrm{~K}$ for winter conditions at latitudes higher than $50^{\circ}$. It decreases by $1-2 \mathrm{~K}$ around $85 \mathrm{~km}$ in the summer high latitudes. It also increases by $2-3 \mathrm{~K}$ between 90 and $100 \mathrm{~km}$ at all latitudes, except around $95 \mathrm{~km}$ at latitudes higher than $70^{\circ}$ during the summer, when it increases by $8 \mathrm{~K}$. In general, the temperature of the mesopause at all latitudes is $1-3 \mathrm{~K}$ larger. In the polar summer, additionally, its altitude is $3-4 \mathrm{~km}$ lower.

- A priori: we now use a more realistic temperature pressure a priori, which is a merging of ECMWF highresolution operational data assimilation and forecasting system temperatures for pressures larger than $0.1 \mathrm{hPa}$ and NRLMSISE-00 otherwise. We note that, given the first-order difference Tikhonov regularization used, the a priori temperatures do not substantially influence the retrieved temperatures directly but constrain predominantly the vertical temperature gradients. This upgrade leads to changes of $\pm 1 \mathrm{~K}$ affecting temperatures above $70 \mathrm{~km}$, except for summer latitudes between 50 and $70^{\circ}$, where the changes are slightly larger (reaching $-2 \mathrm{~K}$ around $75-80 \mathrm{~km}$ ).

- Horizontal gradients within non-LTE populations: the atmosphere changes along the line of sight, particularly when the poles are intercepted during the solstices, and so do the populations of the emitting states. These populations are now corrected for the simultaneously retrieved temperature gradient along the LOS using a significantly improved approach. This results in $1 \mathrm{~K}$ changes affecting latitudes from 50 to $70^{\circ}$ above $80 \mathrm{~km}$ during the summer.

- $\mathrm{H}_{2} \mathrm{O}$ and $\mathrm{O}_{3}$ joint fit: water vapor and ozone contribute to atmospheric radiance around $15 \mu \mathrm{m}$ in the lower stratosphere. The vM11 TLOS retrievals modeled these contributions using $\mathrm{H}_{2} \mathrm{O}$ and $\mathrm{O}_{3}$ abundances from climatologies. Following the retrieval scheme used for the TLOS retrieval in the NOM mode, we now jointly retrieve the water vapor and ozone in order to account for differences between climatological $\mathrm{H}_{2} \mathrm{O}$ and $\mathrm{O}_{3}$ and the abundances prevailing in the measurements. The average changes in temperature are small above $20 \mathrm{~km}$ (i.e., in the MA, UA and NLC temperatures) due to the minor contribution of $\mathrm{H}_{2} \mathrm{O}$ and $\mathrm{O}_{3}$ in the microwindows used.

- Field of view: instead of using three pencil beams for the numerical integration of the signal over the field of view above $40 \mathrm{~km}$, we now use five for the whole altitude range. This change does not significantly affect the retrieved kinetic temperature but leads to a larger convergence ratio in vM21. 

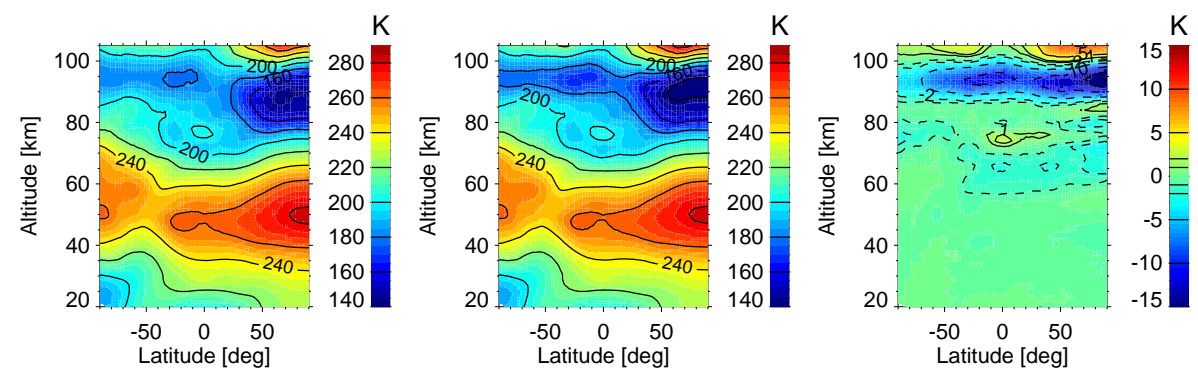

Figure 1. Zonal mean v521 temperature for 3 June 2010 retrieved considering (left) and not considering (center) temperature gradients along the line of sight and difference between both (right). The gradients used for the calculations are those simultaneously retrieved in v521 TLOS retrievals. The contours used are also indicated with horizontal bars on the color bar.
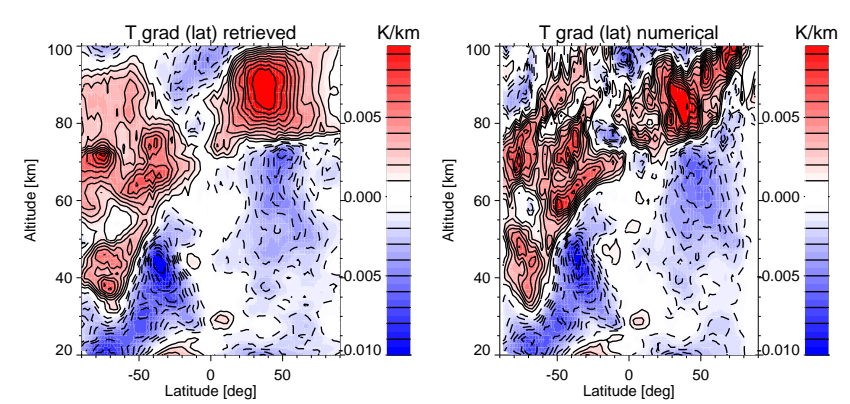

Figure 2. Latitude-altitude cross sections of v521 zonal means of MIPAS kinetic temperature horizontal (meridional) gradients for 15 July 2009. Left panel: directly retrieved; right panel: produced using the retrieved temperature fields.

Other important aspects of the retrieval, including nonLTE collisional rate constants, are set as in the previous vM11 version (refer to GC2012 for more details) with some (minor) non-LTE updates as described in Funke et al. (2012)

Using this retrieval setup, we derived temperatures, line of sight and temperature horizontal gradients for all MIPAS MA, UA and NLC measurements in the optimized resolution, i.e., from January 2005 to April 2012. Figures 3, 4 and 5 show seasonal latitude-altitude zonal means of the retrieved temperatures for the MA, UA and NLC modes, respectively, the corresponding vertical resolutions and the difference with vM11 temperatures. The MA and UA modes cover the four seasons, which include measurements taken during December-January-February (DJF), March-April-May (MAM), June-July-August (JJA), and September-OctoberNovember (SON), and the NLC mode covers two seasons, which include measurements taken in January and July. The averages shown in these figures contain measurements extending only from 2005 to 2009 , but they are representative of the complete period. This has been done for the sake of compatibility with vM11 averages, since the latter were done from 4.61/4.62 spectra, only available for 2005-2009. Our Fig. 3 left and central panels are thus directly comparable to those in Fig. 2 in GC2012.
The latitude-altitude temperature distributions behave similarly in the three modes of observation. The vertical resolution is, however, slightly $(1-2 \mathrm{~km})$ better in the NLC mode from 75 to $90 \mathrm{~km}$, where it decreases with respect to the MA and UA mode due to the finer NLC-mode vertical sampling. The mesopause is also slightly colder, and the lower thermosphere slightly warmer, in the summers in the NLC mode. The higher vertical resolution in the $80-90 \mathrm{~km}$ region accounts for up to $3-4 \mathrm{~K}$ lower NLC temperatures (in the polar summer mesopause). The remaining differences exist because the NLC measurements are taken closer to the solstices whereas the MA and UA measurements are taken regularly through DJF or JJA, i.e., the summers in Fig. 5 show a more extreme scenario than in Figs. 3 and 4.

The vM21 estimated systematic and random temperature errors remain similar to those of versions vM11 (cf. Table 2 of GC2012). The sources of systematic errors considered are the uncertainties in non-LTE errors collisional rates, atomic oxygen abundance, $\mathrm{CO}_{2}$ abundance, $\mathrm{CO}_{2}$ spectroscopic properties (strength, position and width of spectral lines), gain calibration, instrument line shape and spectral shift (see further details on error sources included in GC2012). Systematic errors depend on latitude and season but are typically smaller than $1 \mathrm{~K}$ below $70 \mathrm{~km}, 3 \mathrm{~K}$ at $85 \mathrm{~km}$ and $10 \mathrm{~K}$ at $100 \mathrm{~km}$. For summer high latitudes, these values are larger in the upper mesosphere and above, reaching $6 \mathrm{~K}$ in the mesopause $(88 \mathrm{~km})$ and $30 \mathrm{~K}$ at $100 \mathrm{~km}$. The vM21 temperature random errors are mainly caused by the instrumental noise and are smaller than $0.5 \mathrm{~K}$ below the stratopause and $7 \mathrm{~K}$ at the mesopause. The vertical resolution is barely affected by the version used.

The vM21 temperature differences with respect to vM11 are important, particularly above $80 \mathrm{~km}$ (see Figs. 3-5). The latitude-altitude distribution of the vM21-vM11 temperature difference remains almost invariant with mode in all seasons. The differences in each mode do not significantly vary with season at low latitudes $\left(<30^{\circ}\right)$, but they do at higher latitudes. Beyond $30^{\circ} \mathrm{N} / \mathrm{S}$, differences are larger during solstice than equinox and slightly larger above $80 \mathrm{~km}$ during JJA (or only July in NLC) than during DJF (or only 

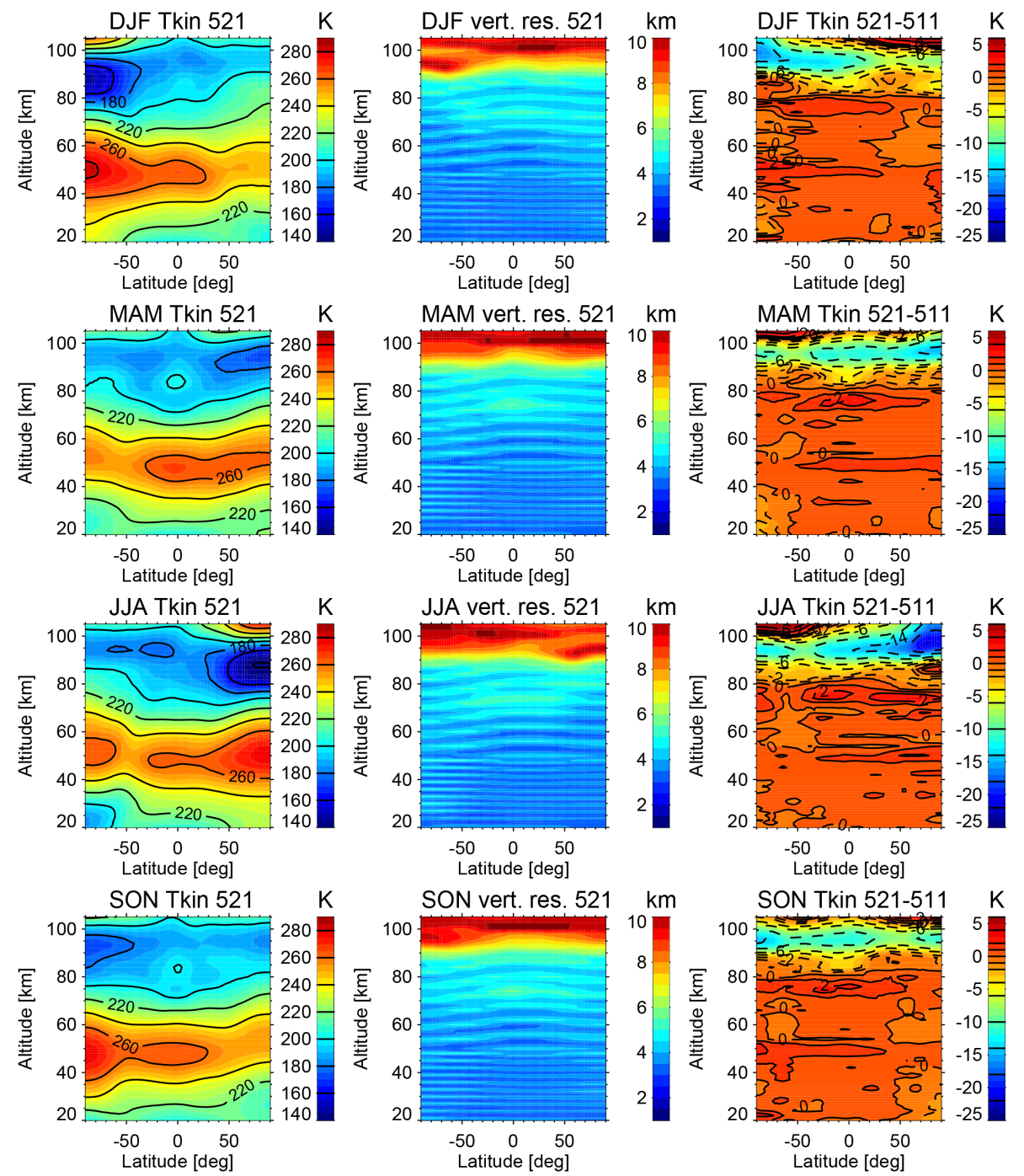

Figure 3. Latitude-altitude cross sections of v521 zonal means of MIPAS MA kinetic temperature (left), its vertical resolution (center) and its difference with v511 (right; contours at $-22,-18,-14,-10,-6,-4,-2,-1,0,1,2,4,6 \mathrm{~K}$ indicated in the color bar) during, from top to bottom, the boreal winter (December-January-February: DJF), vernal equinox (March-April-May; MAM), austral winter (June-JulyAugust: JJA) and autumnal equinox (September-October-November: SON). Only measurements from 2005 to 2009 are included for direct comparison with results in García-Comas et al. (2012).

January in NLC). The latter is explained by interhemispheric differences in the temperature itself. Temperatures during JJA show sharper structure (colder mesopauses and warmer lower thermospheres at all latitudes). In general, those translate into a larger sensitivity to some of the main changes introduced in vM21 retrievals: atomic oxygen, because of the larger non-LTE effects in more extreme atmospheres, or temperature horizontal gradient regularization, because of the larger gradients along the line of sight.

Overall, the effects of these new retrieval setups sum up to a $1-2 \mathrm{~K}$ increase right above the stratopause (maximum in the polar summers), mainly driven by the updated HITRAN spectral database, with a maximum in polar summers due to the additional effect of the MIPAS 5.02/5.06 L1b spectraversion. The effect of the spectral database modulated by that of the L1b spectra version is also the main reason for the increase in temperature (up to $2 \mathrm{~K}$ ) around $75 \mathrm{~km}$ at all latitudes and the $1-2 \mathrm{~K}$ decrease around $80 \mathrm{~km}$ in the polar summer in the NLC mode. Other changes, like those of offset and temperature horizontal gradient regularizations, as well as apodization accuracy and a priori in the polar summer, also affect temperature below $80 \mathrm{~km}$, but to a lesser extent.

The vM21 temperatures above $80 \mathrm{~km}$ and up to $102 \mathrm{~km}$, in general, decrease with respect to vM11 at most latitudes and seasons (except around the summer high latitudes $\left(>60^{\circ}\right)$ mesopause; see below), with maximum (in absolute value) negative differences at the mesopause $(-10 \mathrm{~K}$ around $95 \mathrm{~km}$ and slightly smaller in the Arctic winter). This decrease in 

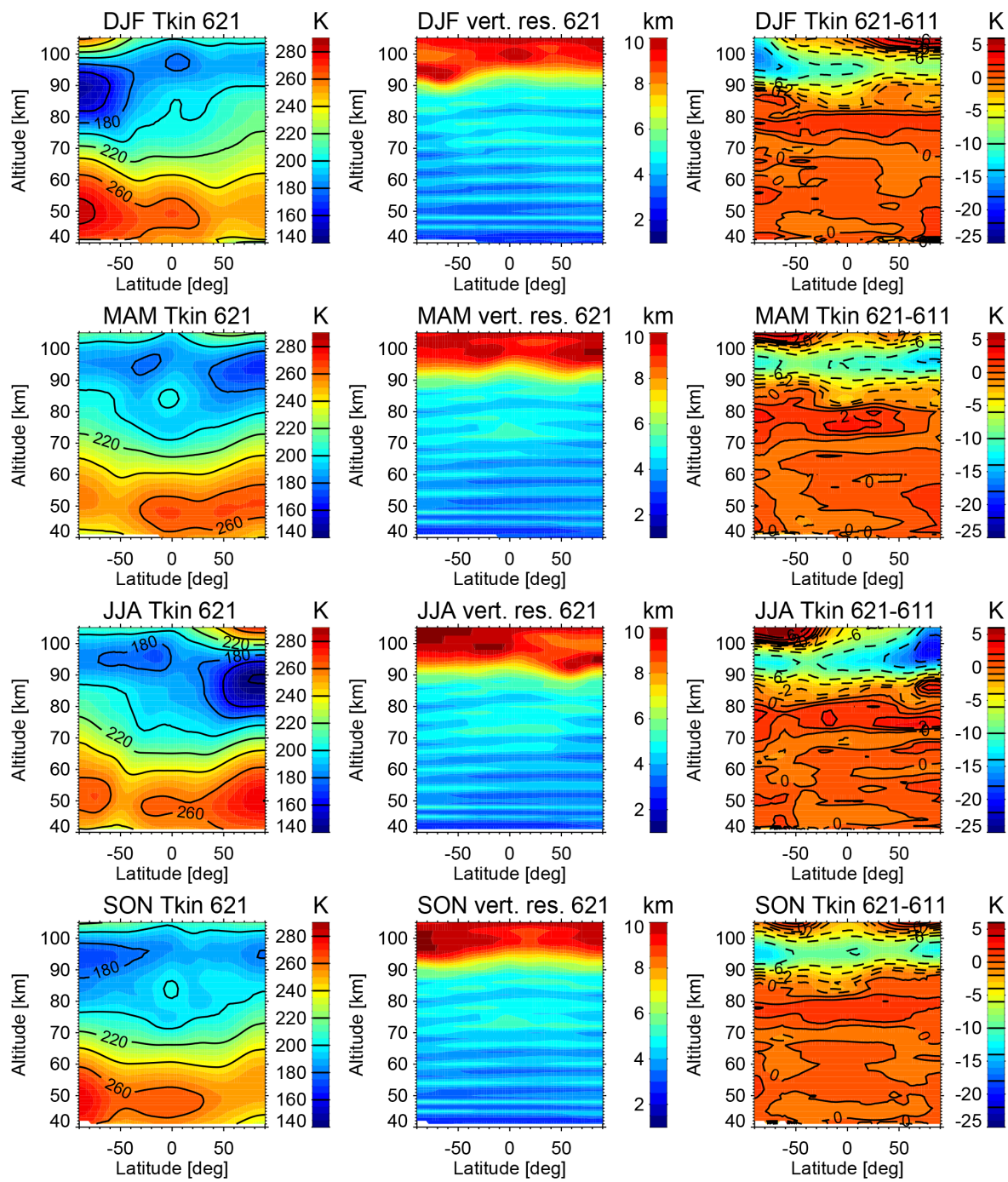

Figure 4. Latitude-altitude cross sections of v621 zonal means of MIPAS UA kinetic temperature (left), its vertical resolution (center) and its difference with v611 (right) during, from top to bottom, the boreal winter (DJF), vernal equinox (MAM), austral winter (JJA) and autumnal equinox (SON).

temperature is mainly due to the 5.02/5.06 L1b spectra version, although effects from changes in (in this order) (i) the temperature horizontal gradient regularization (particularly at the mesopause at low latitudes), (ii) the atomic oxygen (particularly above the mesopause), (iii) the offset regularization and the apodization accuracy (particularly below the mesopause), and (iv) the carbon dioxide (in the polar winter) are not negligible (1-3 K, in absolute values).

The exception to that general behavior occurs at the summer high latitudes $\left(>60^{\circ}\right)$. The mesopause there, at lower altitude and temperature than in other latitudes and seasons, is $2-4 \mathrm{~K}$ warmer and $3-4 \mathrm{~km}$ lower in vM21, mainly due to the increase caused by the updated atomic oxygen, which is partially compensated for by a $2-3 \mathrm{~K}$ decrease caused by the improved offset and temperature horizontal gradient regularizations. As in other atmospheric conditions, the temperature in the summer high latitudes decreases by $4 \mathrm{~K}$ at $90 \mathrm{~km}$, due to the combined effect of the changes in the L1b spectra, the temperature horizontal gradient regularization, the $\mathrm{CO}_{2}$ abundance and the offset regularization. However, the response to changes above $95 \mathrm{~km}$ is amplified due to the significantly larger temperature vertical gradient, which additionally leads to higher temperatures (which result in larger non-LTE effects), and the larger temperature gradients along the line of sight. When upgrading from vM11 to vM21, the temperature decrease around $100 \mathrm{~km}$ at high latitudes is $-15 \mathrm{~K}$ in the austral summer and $-20 \mathrm{~K}$ in the boreal summer, mainly due to the atomic oxygen and the L1b spectra version, but also to the temperature horizontal gradient regularization and the $\mathrm{CO}_{2}$ abundance (effects are larger than $3 \mathrm{~K}$, in absolute values). 

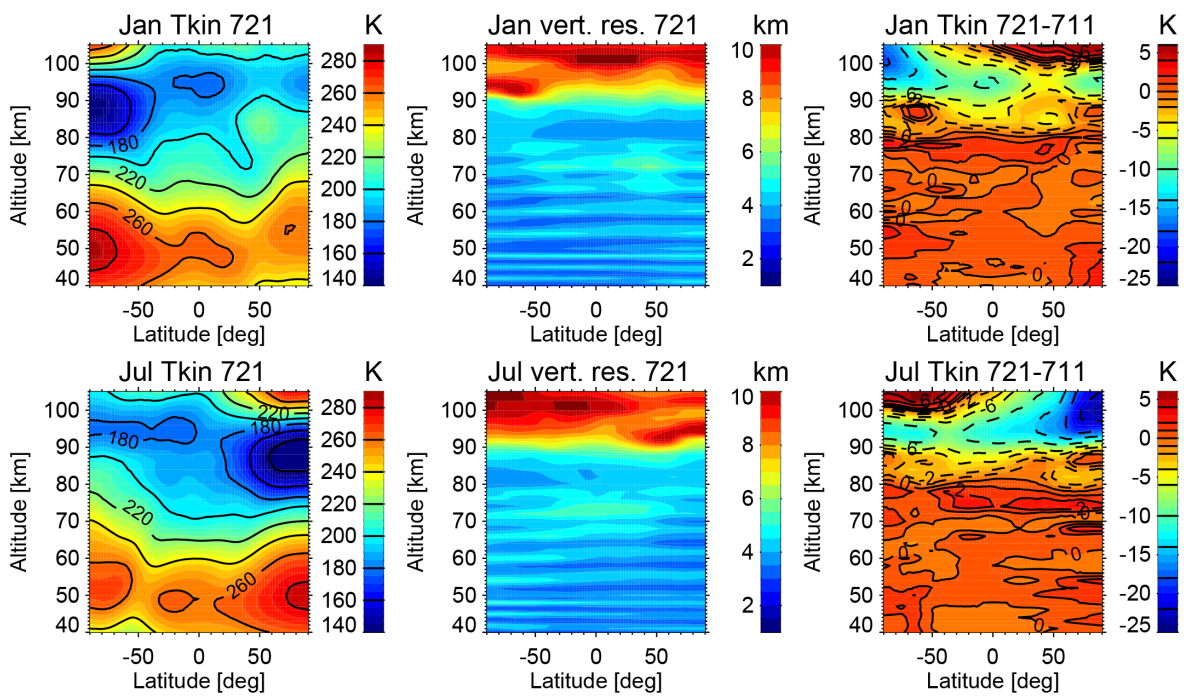

Figure 5. Latitude-altitude cross sections of v721 zonal means of MIPAS NLC kinetic temperature (left), its vertical resolution (center) and its difference with v711 (right) during January (top) and July (bottom) (note that MIPAS measured in NLC mode only around the solstices).

\section{Instruments used for comparison}

In order to assess the quality of the MIPAS temperatures derived using vM21 retrievals, we compare our results with close-to-simultaneous remote measurements from seven instruments. Besides the comparison with two lidars on the ground, we include five other satellite instruments that, together with MIPAS, provided temperature in the MLT on a regular basis over long periods (longer than 5 years) between January 2005, when the vM21 retrievals start, and April 2012, when MIPAS stopped operations.

\subsection{Lidars}

We use for our comparisons measurements from the two NASA Jet Propulsion Laboratory Rayleigh and Raman differential absorption lidars: one located at the Table Mountain Facility (TMF) $\left(34^{\circ} \mathrm{N}, 118^{\circ} \mathrm{W}\right)$ and the other one at the Mauna Loa Observatory (MLO) $\left(20^{\circ} \mathrm{N}, 156^{\circ} \mathrm{W}\right)$. They provide nighttime temperatures from $12 \mathrm{~km}$ to $80-85 \mathrm{~km}$ with a $300 \mathrm{~m}$ vertical sampling, and a vertical resolution of $1-2 \mathrm{~km}$ from 10 to $65 \mathrm{~km}$ and $2-4 \mathrm{~km}$ from 65 to $80 \mathrm{~km}$. Temperature precision is better than $1 \mathrm{~K}$ below $55 \mathrm{~km}$ and $5 \mathrm{~K}$ at $80 \mathrm{~km}$. Systematic errors are $4 \mathrm{~K}$ below $25 \mathrm{~km}$, less than $1 \mathrm{~K}$ at $30-60 \mathrm{~km}$ and $10 \mathrm{~K}$ at $80 \mathrm{~km}$ (Leblanc et al., 1998a). A detailed description of the lidar error sources is also provided in Leblanc et al. (1998).

\subsection{ACE-FTS}

The ACE-FTS is the Fourier transform spectrometer onboard the Canadian-led scientific satellite SciSat-1 (also known as ACE, the Atmospheric Chemistry Experiment). It is a solar occultation high-resolution $\left(0.02 \mathrm{~cm}^{-1}\right.$, unapodized $)$ instrument, covering daily a narrow range of latitudes, which depend on season, but achieving near-global coverage over the course of a year. ACE-FTS provides temperature from $\mathrm{CO}_{2}$ transmittance measurements from 15 to $125 \mathrm{~km}$. NonLTE effects are not considered in these retrievals but the selection of microwindows was done to minimize these effects: the microwindows above $70 \mathrm{~km}$ cover absorption lines from common lower state (ground level) vibrational bands. The vertical sampling ranges typically from $1 \mathrm{~km}$ in the midtroposphere to $3-4 \mathrm{~km}$ above the mid-stratosphere, and the vertical resolution is limited to $3-4 \mathrm{~km}$ (Boone et al., 2013). We use v3.0 temperatures here. No estimates of the systematic errors are currently available.

\subsection{MLS}

The Microwave Limb Sounder (MLS), launched on the NASA Aura satellite in 2004, provides daily nearly global $\left(82^{\circ} \mathrm{N}-82^{\circ} \mathrm{S}\right)$ profiles of temperature and trace gases from 316 to $0.001 \mathrm{hPa}(\approx 10$ to $97 \mathrm{~km})$ from observations of the atmospheric limb at millimeter and submillimeter wavelengths. Retrieved temperature is derived primarily from oxygen emission at 118 and $239 \mathrm{GHz}$, and is not impacted by cirrus ice, aerosols or effects of non-LTE. Here we use v3.3 of MLS temperature, which is similar to v2.2 described in Schwartz et al. (2008) (differing in the number of stratospheric retrieval levels and reduced vertical smoothing in the mesosphere and lower thermosphere). Vertical resolution is $5 \mathrm{~km}$ from 261 to $100 \mathrm{hPa}, 3.6 \mathrm{~km}$ at $31.6 \mathrm{hPa}, 4.3 \mathrm{~km}$ at $10 \mathrm{hPa}, 6 \mathrm{~km}$ at $0.1 \mathrm{hPa}$ and $\approx 10 \mathrm{~km}$ at $0.001 \mathrm{hPa}$. Precision is generally better than $1 \mathrm{~K}$ at retrieval pressures above $1 \mathrm{hPa}$ and degrades from 1 to $3 \mathrm{~K}$ between 1 and $0.001 \mathrm{hPa}$. In the stratosphere, MLS has an $\sim 1 \mathrm{~K}$ mean low bias with additional oscillatory structure on the order of $\pm 1 \mathrm{~K}$ compared 
to correlative data. Biases are more poorly characterized, but generally negative in the mesosphere/lower thermosphere.

\subsection{OSIRIS}

OSIRIS (Optical Spectrograph and InfraRed Imaging System), onboard the Odin satellite, launched in 2001, observes the Earth's limb between 7 and $110 \mathrm{~km}$ with a $1.5 \mathrm{~km}$ vertical sampling and covers latitudes lower than $82^{\circ}$ in both hemispheres. Its spectral resolution is $1 \mathrm{~nm}$. Temperatures are derived from measurements of the Rayleigh scattered sunlight at $318.5 \mathrm{~nm}$ from 45 to $72 \mathrm{~km}$ and $347.5 \mathrm{~nm}$ from 72 to $85 \mathrm{~km}$, and from the measurements of the $\mathrm{O}_{2} \mathrm{~A}$-band airglow at $762 \mathrm{~nm}$ from 85 to $105 \mathrm{~km}$. Systematic errors are less than $2 \mathrm{~K}$ below $72 \mathrm{~km}$, less than $3 \mathrm{~K}$ at $72-77 \mathrm{~km}$ and $8 \mathrm{~K}$ around $85 \mathrm{~km}$ (Sheese et al., 2012, and references therein). Measurements are affected by mesospheric cloud contamination but these are filtered out. Odin is in a Sun-synchronous orbit, with ascending/descending nodes at 06:00/18:00 LT.

\subsection{SABER}

SABER (Sounding of the Atmosphere using Broadband Emission Radiometry), onboard NASA's TIMED (Thermosphere Ionosphere Mesosphere Energetics Dynamics) satellite, is a broadband radiometer measuring temperature from 20 to $120 \mathrm{~km}$ since 2002. SABER measures day- and nighttime temperatures almost globally $\left(52-82^{\circ}\right)$, alternating every 2 months between northern $\left(52^{\circ} \mathrm{S}-82^{\circ} \mathrm{N}\right)$ and southern $\left(82^{\circ} \mathrm{S}-52^{\circ} \mathrm{N}\right)$ almost-polar coverage. As with vM21 MIPAS temperatures, SABER's temperatures are derived from measurements of the $\mathrm{CO}_{2}$ limb radiance at $15 \mu \mathrm{m}$, also requiring non-LTE calculations in the retrievals. SABER vertical grid is $400 \mathrm{~m}$ and its vertical resolution is $2 \mathrm{~km}$. Typical SABER estimates of v1.07 temperature random errors are $<0.5 \mathrm{~K}$ below $55 \mathrm{~km}, 1 \mathrm{~K}$ at $70 \mathrm{~km}, 2 \mathrm{~K}$ at $85 \mathrm{~km}$ and $7 \mathrm{~K}$ at $100 \mathrm{~km}$, and systematic errors are $<1.5 \mathrm{~K}$ below $55 \mathrm{~km}, 0.5 \mathrm{~K}$ at $70 \mathrm{~km}$, $4 \mathrm{~K}$ at $85 \mathrm{~km}$ and $5 \mathrm{~K}$ at $100 \mathrm{~km}$ (Remsberg et al., 2008; García-Comas et al., 2008). Here we use SABER v2.0 temperatures. A thorough validation of these temperatures has not yet been published, nor have the differences of the v2.0 temperatures with v1.07. Nevertheless, the v2.0 estimated systematic and random errors are not expected to change much from v1.07 since the uncertainties of their sources are the same. We note that the non-LTE collisional rates used in SABER v2.0 temperatures are as in MIPAS vM21, $\mathrm{CO}_{2}$ abundance is taken from WACCM but not WACCM-SD, and atomic oxygen concentration is derived from SABER's measurements.

\section{SOFIE}

SOFIE (Solar Occultation For Ice Experiment), onboard NASA's AIM (Aeronomy of Ice in the Mesosphere) satellite, is SABER's heritage but performs the broadband observations using the solar occultation technique. SOFIE covers latitudes from 65 to $85^{\circ}$ in each hemisphere. It started its operations in 2007 and has been providing temperature measurements nearly continuously since then. Temperature is derived with $1 \mathrm{~km}$ vertical resolution from measurements of atmospheric refraction at $701 \mathrm{~nm}$ from 15 to $55 \mathrm{~km}$ and with $2 \mathrm{~km}$ vertical resolution from measurements of transmission in the $4.3 \mu \mathrm{m} \mathrm{CO}$ band from 50 to $102 \mathrm{~km}$, both in a $200 \mathrm{~m}$ vertical grid. SOFIE's v1.2 temperature retrievals, which we use here, include consideration of non-LTE, although these effects are less important on occultation than on emission measurements. We note that the non-LTE collisional rates used in SOFIE v1.2 temperatures are as in MIPAS vM21. The $\mathrm{CO}_{2}$ abundance assumed for the retrievals is taken from a WACCM climatology, and atomic oxygen abundance is taken from NRLMSISE-00 empirical model. SOFIE v1.2 temperature systematic errors are smaller than $1 \mathrm{~K}$ below $40 \mathrm{~km}, 3 \mathrm{~K}$ at $50 \mathrm{~km}, 3 \mathrm{~K}$ at $85 \mathrm{~km}(6 \mathrm{~K}$ in the polar summer), and around $10 \mathrm{~K}$ at $100 \mathrm{~km}$ (Marshall et al., 2011).

\section{Differences in temperatures between instruments}

We determined the colocated measurements of each instrument and MIPAS measurements from January 2005 to April 2012 in its MA, UA and NLC modes of operation. The measurements in a colocated pair are taken at a maximum of $2 \mathrm{~h}$ and $1000 \mathrm{~km}$ apart. These criteria minimize differences coming from atmospheric variability without compromising the statistical significance of the comparisons. In order to optimize this balance, we have performed tests by increasing and decreasing both the spatial and temporal differences between the measurements. Decreasing the distance and the time difference between colocated pairs to $500 \mathrm{~km}$ and $1 \mathrm{~h}$, respectively, barely changes the results. For a given pair, we use the averaging kernels and a priori of the coarser vertical resolution instrument to smooth the colocated profile of the finer-resolution one. That is, we smooth lidars' SABER, SOFIE, and OSIRIS profiles in their comparisons with MIPAS, and MIPAS in its comparison with MLS. Given their similar vertical resolution, we do not smooth MIPAS or ACE-FTS profiles in their comparison. We use altitude as the vertical coordinate for all comparisons except for those between MIPAS and MLS, for which we use pressure.

We calculated the temperature difference for each pair of profiles, and then their yearly averages for colocations within $20^{\circ}$ wide latitude boxes for four periods: DJF, MAM, JJA and SON. We then calculated the mean for each season and latitude box. The spring averages encompass the measurements during MAM in the Northern Hemisphere (NH) and SON in the Southern Hemisphere (SH), autumn during SON in the $\mathrm{NH}$ and MAM in the SH, summer during JJA in the NH and DJF in the SH, and winter during DJF in the NH and JJA in the $\mathrm{SH}$.

Figures 6-9 show the average seasonal differences for the four seasons in the MA mode and Figs. 10 and 11 for summer 


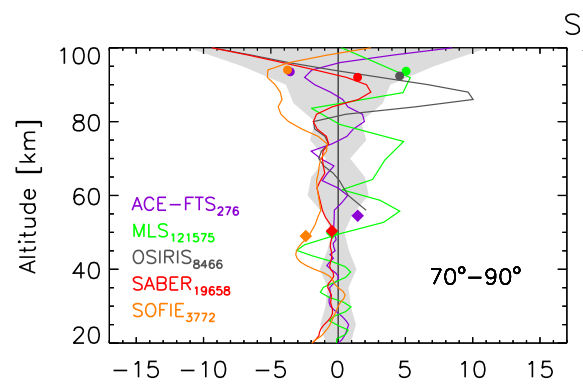

Spring
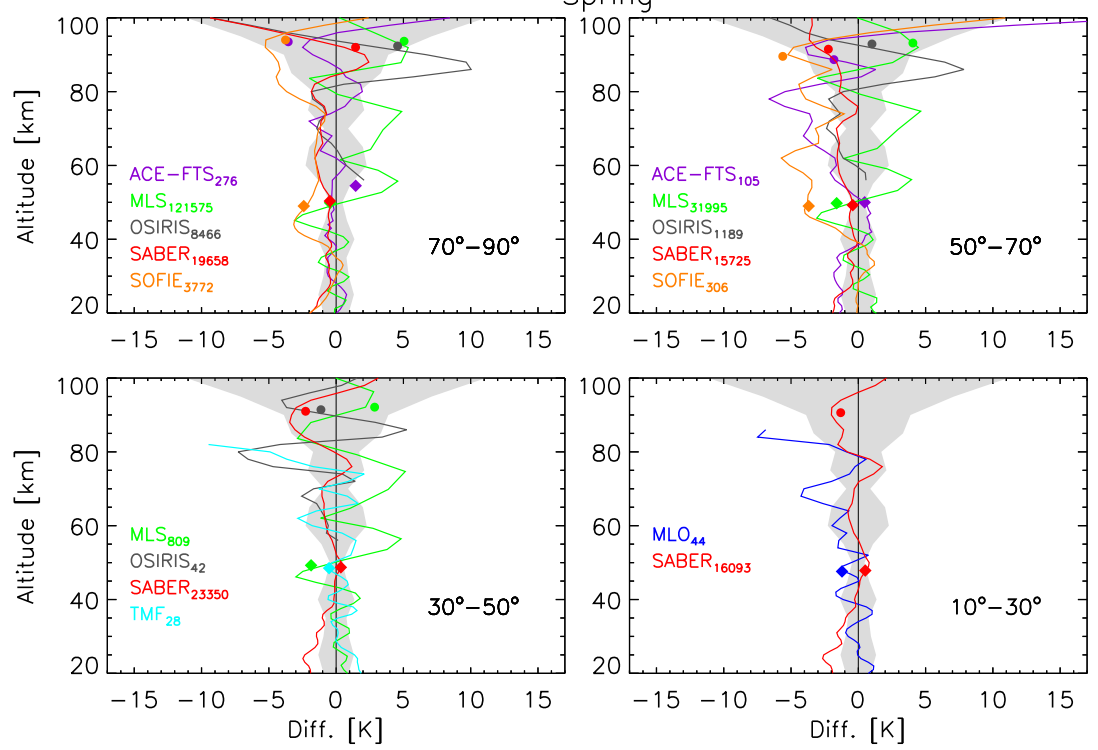

Figure 6. Spring (MAM for NH and SON for SH) mean temperature differences (MIPAS-instrument) between colocated pairs of measurements of MIPAS (MA mode) and ACE-FTS (purple), MLS (green), OSIRIS (grey), SABER (red), SOFIE (orange), and the Table Mountain (light blue) and Mauna Loa (dark blue) lidars. The number of MIPAS coincidences with each instrument within $2 \mathrm{~h}$ and $1000 \mathrm{~km}$ is indicated in the corresponding subscript. Differences in the stratopause (diamond) and mesopause (circle) temperatures at their corresponding altitude in MIPAS averaged colocated profiles are indicated. Shaded areas include MIPAS-only systematic errors.

and winter in the NLC mode. Note that, even if we determined the differences as a function of pressure in the MIPAS versus MLS comparison, we plot them as a function of MIPAS altitude for the sake of simplicity. Results for the comparisons of colocated measurements in the UA mode (see Supplement) are almost identical to those in the MA mode. The figures also include the estimated MIPAS temperature systematic errors and the number of coincidences for each season and latitude box. Using only MIPAS errors represents a pessimistic scenario because, strictly speaking, the temperature differences should be compared with the combined systematic errors for each instrument pair, which necessarily have larger values than the shading in the figures. Differences in temperatures of the stratopause (point in the temperature-altitude average profile with maximum temperature in the stratosphere and lower mesosphere region) and mesopause (point with minimum average temperature in the upper mesosphere and lower thermosphere region), even if they are located at different altitudes in each pair of instruments, are also plotted using symbols at their corresponding mean altitudes in MIPAS colocated profiles. When these symbols are exactly over the difference profiles, this indicates that the two instruments under consideration located the strato- and/or the mesopauses at the same altitude.

\subsection{From the lower stratosphere to the middle mesosphere}

MIPAS temperatures typically differ from measurements from the other instruments on satellites and the lidars less than $1 \mathrm{~K}$ in the stratosphere at all latitudes and in all seasons (Figs. 6-9). The altitudes of MIPAS and the other instruments stratopauses do not differ significantly. The stratopause temperature differences are normally less than $1 \mathrm{~K}$. Differences at $50-80 \mathrm{~km}$ are typically less than $2 \mathrm{~K}$ at latitudes lower than $50^{\circ}$ for all seasons and at higher latitudes during spring, autumn and winter. At the summer high latitudes $\left(>50^{\circ}\right)$, differences are, in general, smaller than $2 \mathrm{~K}$ at $50-65 \mathrm{~km}$ and $5 \mathrm{~K}$ at $65-80 \mathrm{~km}$. The differences in the middle mesosphere are generally negative (except for some comparisons during winter), i.e., MIPAS sees a slightly colder middle mesosphere. Besides the polar summer above $40 \mathrm{~km}$, these values are within MIPAS systematic error estimates.

Exceptions to the typical behavior described above occur at the following altitudes:

- Around $20 \mathrm{~km}$, in all comparisons with SABER and at $70-90^{\circ}$ in comparisons with SOFIE: MIPAS temperatures are $2 \mathrm{~K}$ lower there than these other two instruments. We do not assign these differences to a bias in MIPAS temperatures because they had been previously reported in SABER v1.07 comparisons with other instruments (Remsberg et al., 2008) and they persist in 

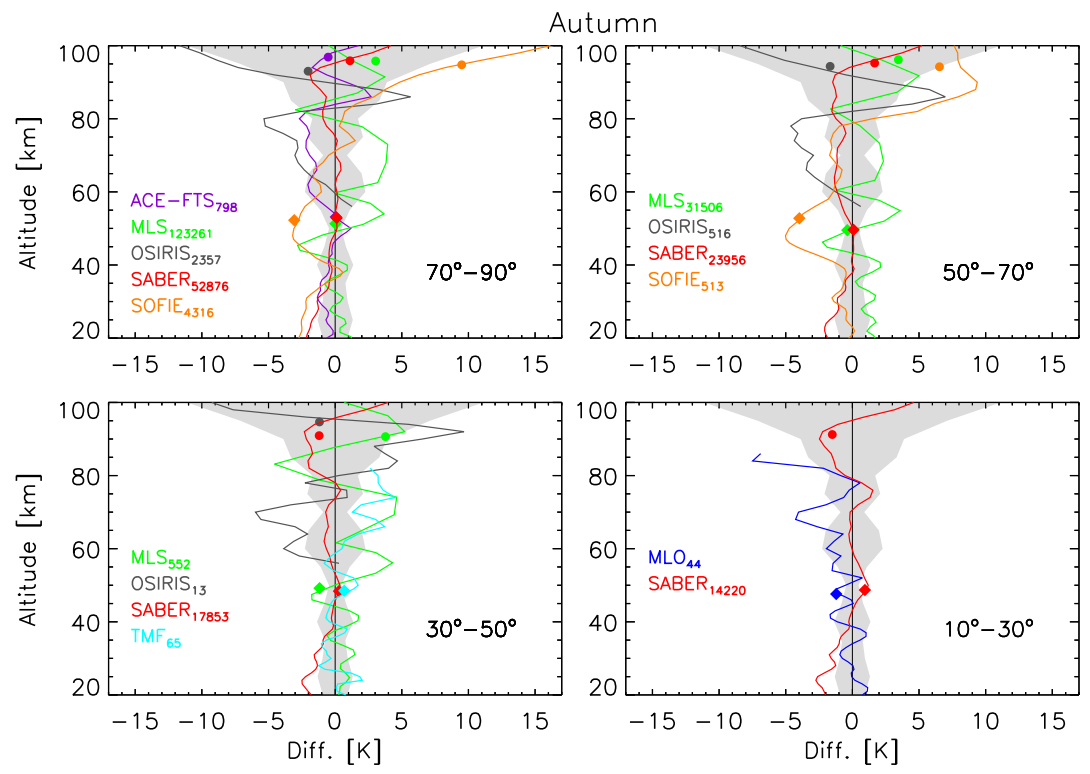

Figure 7. As in Fig. 6 but for autumn (SON for NH and MAM for SH) colocations.

v2.0 (used here). SOFIE behaves as SABER at $70-90^{\circ}$ at these altitudes.

- Around $20 \mathrm{~km}$, in comparisons with ACE-FTS in the winter at $70-90^{\circ}$, where MIPAS provides $5 \mathrm{~K}$ lower temperatures. This behavior is persistent mostly in $\mathrm{SH}$ observations, for all years where coincidences are available, and also in the NH in 2011.

- Around $45 \mathrm{~km}$ during the winter in comparisons with the TMF lidar, where MIPAS and SABER measure $3 \mathrm{~K}$ lower temperatures than the lidar. The differences are slightly larger than the MIPAS and lidar combined estimated systematic error at this altitude $(\sim 2 \mathrm{~K})$ and occurs systematically during this season.

- At 40-60 km, in comparisons with SOFIE at latitudes larger than $50^{\circ}$, where MIPAS's temperature is $3-5 \mathrm{~K}$ colder than SOFIE's, generally peaking at the stratopause. These differences are larger at $50-70^{\circ}$ than at $70-90^{\circ}$ in all seasons. A SOFIE warm bias was also found by Marshall et al. (2011) and Stevens et al. (2012) in comparisons with ACE, SABER and MLS.

- At 40-60 km, in comparisons with ACE-FTS around the poles $\left(>70^{\circ}\right)$ during summer, when MIPAS temperatures are $3 \mathrm{~K}$ higher. This difference was not present in the MIPAS vM11 comparisons with ACE-FTS v2.2 of GC2012. Since MIPAS vM21 temperatures increase $1 \mathrm{~K}$ in this region, the larger difference is probably due to changes (only under these conditions) from ACE-FTS v2.2 to v3.0.
- At 45-80 km, in comparisons with MLS, where MIPAS exhibits lower temperatures at $45-55 \mathrm{~km}$ (up to $3-5 \mathrm{~K}$ at the summer stratopause), except in the winter high latitudes (1-2 K warmer), and 3-4 K higher temperatures at $55-75 \mathrm{~km}$, peaking usually around $55-60$ and $70-75 \mathrm{~km}$. This behavior persists in all seasons and at all latitudes but does not show up in MIPAS comparisons with the other instruments, so it is not likely due to a MIPAS bias. As mentioned above, MLS biases are generally negative in the mesosphere, which may partially or completely explain these differences.

- Around $60 \mathrm{~km}$ during the winter and $70-80 \mathrm{~km}$ during the summer (and, to a lesser extent, in spring and autumn), in comparisons with the MLO lidar (at low latitudes), where both MIPAS and SABER show 3-4 K lower temperatures. These differences lie well within lidar-estimated systematic errors at these altitudes, ranging from $1 \mathrm{~K}$ at $60 \mathrm{~km}$ to $10 \mathrm{~K}$ at $80 \mathrm{~km}$ (Leblanc et al., 1998a), combined with those from MIPAS $(\approx 2 \mathrm{~K})$.

- At 65-80 km, in comparisons with OSIRIS during summer and autumn but not in spring (no information for winter), when the negative differences $(-3$ to $-5 \mathrm{~K})$ are slightly larger, in absolute values. OSIRIS temperatures at these altitudes are affected by a $3 \mathrm{~K}$ systematic error and thus the difference is almost within MIPAS and OSIRIS combined error. Note that Sheese et al. (2012) also found these differences in OSIRIS-SABER comparisons. Note also that, except for the summer $70-90^{\circ}$ box, MIPAS and SABER are within $1 \mathrm{~K}$ at these altitudes. 

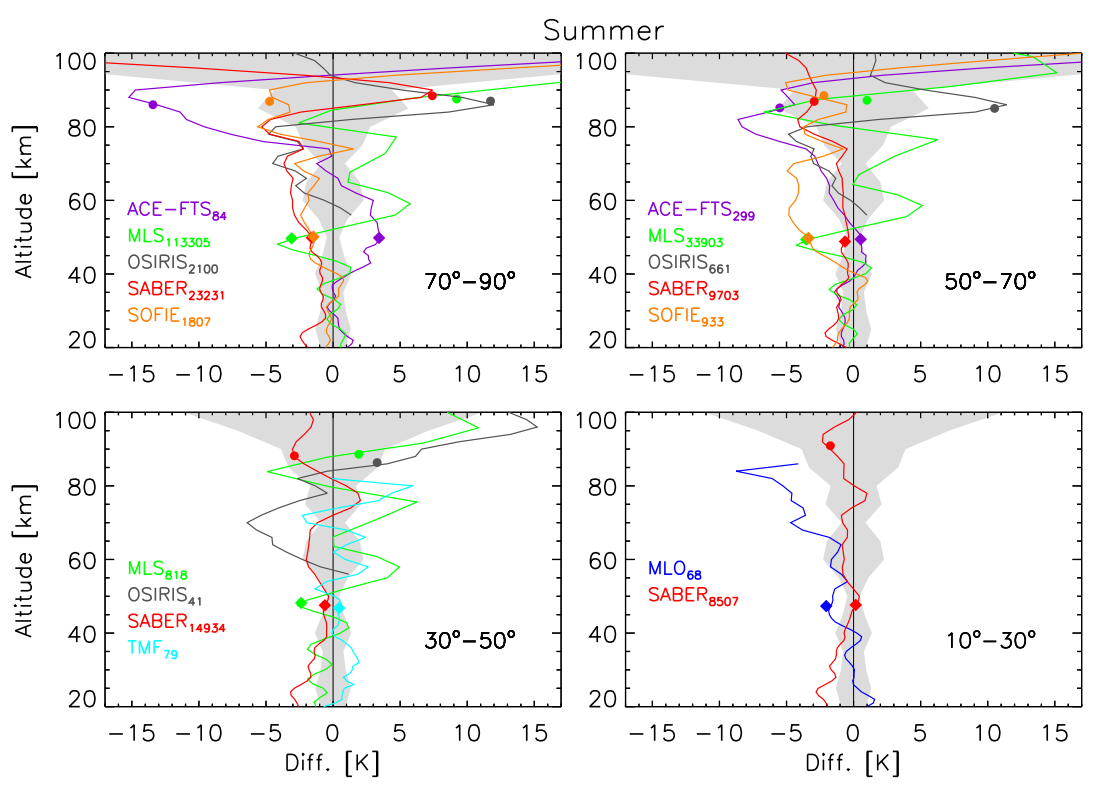

Figure 8. As in Fig. 6 but for summer (JJA for NH and DJF for SH) colocations.

- Around $80 \mathrm{~km}$ in the summer in comparisons with ACE-FTS, where the negative difference is significantly larger than in comparisons with the other instruments and reaches $10 \mathrm{~K}$. A warm bias in ACEFTS summer temperatures has already been reported in Sica et al. (2008) for v2.2 temperatures.

It is important to highlight the excellent results that the comparisons between MIPAS and SABER show. Differences in temperatures measured by these two instruments are smaller than $1 \mathrm{~K}$ below $80 \mathrm{~km}$ all year round, except for the lowermost altitudes $(-1$ to $-2 \mathrm{~K})$ and the mesosphere only during summer at latitudes higher than $70^{\circ}(-3 \mathrm{~K})$ and winter at $50-70^{\circ}(+2 \mathrm{~K})$. This behavior - which is significantly improved with respect to the previous comparisons in GC2012, where MIPAS vM11 was compared with SABER v1.7, and persistent in almost all seasons and latitudes demonstrates the excellent performance of both instruments and their temperature retrievals.

The differences with most instruments present a narrow $(10 \mathrm{~km})$ oscillation centered around $75 \mathrm{~km}$ with $1-2 \mathrm{~K}$ temperature amplitude and which shows up in comparisons with all instruments and corresponds to an oscillation which systematically appears in vM21 temperature vertical gradients and not in the other data sets. This small oscillation is more prominent during the summers. Its cause is still unknown.

The following two aspects related to comparisons with ACE-FTS are noteworthy. First, even within the limits detailed above for the high latitudes, the differences between MIPAS and ACE-FTS temperatures in the lower mesosphere $(z<70 \mathrm{~km})$ are $1-2 \mathrm{~K}$ larger (in absolute value) at $50-70^{\circ}$ than at higher latitudes $\left(70-90^{\circ}\right)$ all year round, which is not the general behavior in MIPAS comparisons with other instruments.

Second, we have paid special attention to a potential change in the behavior of the differences after October 2010, the date from which ACE-FTS v3.0 temperature profiles might be affected by problems related to the pressure registration around $15 \mathrm{~km}$ (taken from the Canadian Meteorological Centre), which may have lead to a maximum altitude offset on the order of $1 \mathrm{~km}$. We found colocations with MIPAS after then only during spring in the $50-70^{\circ} \mathrm{N}$ latitude box and during spring and winter in the $70-90^{\circ} \mathrm{N}$ box. The differences with MIPAS do not change significantly for the former case with respect to previous springs. They do for the latter case, but only in the lower stratosphere, where ACE-FTS temperatures are 4-5 K warmer than on average. Above the mid-stratosphere, the differences for these season-latitude boxes do not differ significantly from the average difference.

\subsection{From the upper mesosphere to the lower thermosphere}

Differences at altitudes above $85 \mathrm{~km}$ are more variable, and depend on instrument, season and latitude.

At latitudes lower than $50^{\circ}$, MIPAS mesopause temperatures are $1-2 \mathrm{~K}$ lower than SABER's (except for winter in the MA mode, when their temperatures coincide on average) and the mesopause is located at the same altitude in winter and summer but not in spring and autumn (where MIPAS mesopause is slightly lower: $2-3 \mathrm{~km}$ ). It is $2-3 \mathrm{~K}$ warmer than MLS's and located at the same altitude. It is $1 \mathrm{~K}$ colder than OSIRIS's in spring and autumn and $3 \mathrm{~K}$ warmer in summer, although not many coincidences were found then, due 

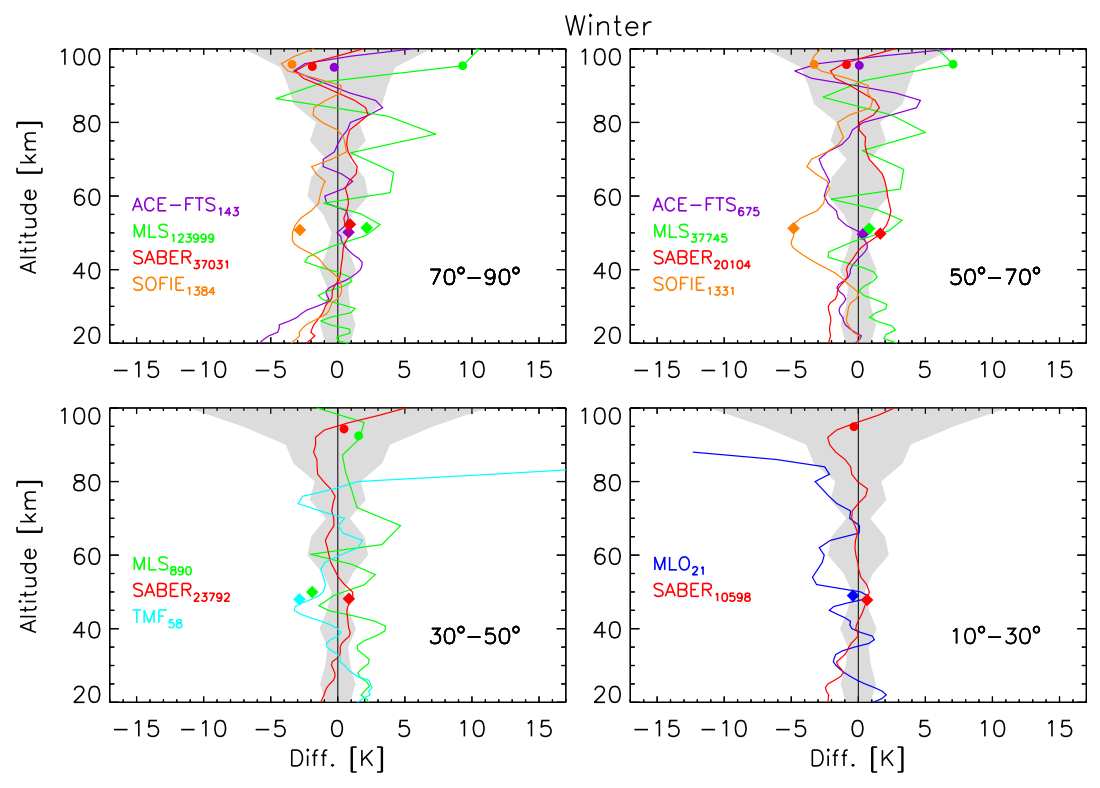

Figure 9. As in Fig. 6 but for winter (DJF for NH and JJA for SH) colocations.

to the difference in the ascending/descending local times of the two instruments. Above $95 \mathrm{~km}$, MIPAS is usually $0-4 \mathrm{~K}$ warmer than the other instruments at these latitudes, except in comparisons with MLS and OSIRIS in the summer, when these two exhibit significantly smaller temperature vertical gradients than the rest, leading to differences of up to 10 and $15 \mathrm{~K}$, respectively.

With the summer high latitudes set aside, MIPAS mesopause temperatures at latitudes higher than $50^{\circ}$ lie between the measurements from the other instruments. MIPAS mesopauses are within $2 \mathrm{~K}$ of those of SABER (colder in winter and warmer in autumn), within $3 \mathrm{~K}$ of those of OSIRIS (warmer in spring and colder in autumn); $1-4 \mathrm{~K}$ colder than ACE-FTS; 3-5 and 7-9 K warmer than MLS in the equinoxes and the winter, respectively; and $4-5 \mathrm{~K}$ colder in spring and winter and $7-10 \mathrm{~K}$ warmer in autumn than SOFIE. Except for a few cases (some spring comparisons with ACE-FTS and SOFIE, autumn with SOFIE or MLS or winter with ACE-FTS), MIPAS mesopauses are located at altitudes differing by less than $1-2 \mathrm{~km}$. Note that ACE-FTS mesopause in winter is located $6 \mathrm{~km}$ higher even though its temperature is the same as in MIPAS. Except for SABER in autumn and spring, MIPAS temperatures around $85 \mathrm{~km}$ at these latitudes are generally from 2 to $5 \mathrm{~K}$ warmer (OSIRIS and SOFIE present slightly larger differences). Except in comparisons with OSIRIS and SABER in spring, MIPAS temperatures in the lower thermosphere are $1-7 \mathrm{~K}$ warmer than the other instruments.

As for altitudes below $85 \mathrm{~km}$, comparisons between SABER and MIPAS are also particularly good above that altitude, showing differences smaller than $2 \mathrm{~K}$ at $80-95 \mathrm{~km}$ except during summer at high latitudes.
Differences above $85 \mathrm{~km}$ in the summer high latitudes are larger than under any other conditions examined. MIPAS mesopause $(\approx 88 \mathrm{~km})$ temperatures also lie within the other instrument measurements, but the differences (in absolute values) reach significantly larger values around the poles. On average, they are $7-12 \mathrm{~K}$ warmer than MLS, SABER and OSIRIS, and 5 and $14 \mathrm{~K}$ colder than SOFIE and ACEFTS, respectively. Results from previous comparisons with other instruments from SOFIE and ACE-FTS (Stevens et al., 2012; Sica et al., 2008) resulted in reported likely positive biases for them around the mesopause. MIPAS temperatures in the polar summer mesopause would better agree with those measured by MLS, SABER and OSIRIS if an atomic oxygen concentration smaller than that of WACCMSD were used in MIPAS retrievals in that region. Nevertheless, the altitude of the mesopause is very similar for all instruments $(\approx 88 \mathrm{~km})$. The differences above $90 \mathrm{~km}$ are positive, except for SABER comparisons, and generally larger than $15 \mathrm{~K}$, except for OSIRIS comparisons. The differences in the lower thermosphere increase with altitude, reflecting a larger temperature vertical gradient in MIPAS (and particularly SABER) measurements.

\section{NLC-mode temperature differences}

We examine in detail here the comparisons of MIPAS temperatures retrieved from NLC-mode measurements with those from other instruments and their differences with respect to the comparisons of the other modes, which have a coarser vertical sampling in the upper mesosphere.

Temperature differences with the other instruments in summer and winter in the NLC mode (Figs. 10 and 11) show a similar behavior to those in the MA mode (Figs. 8 

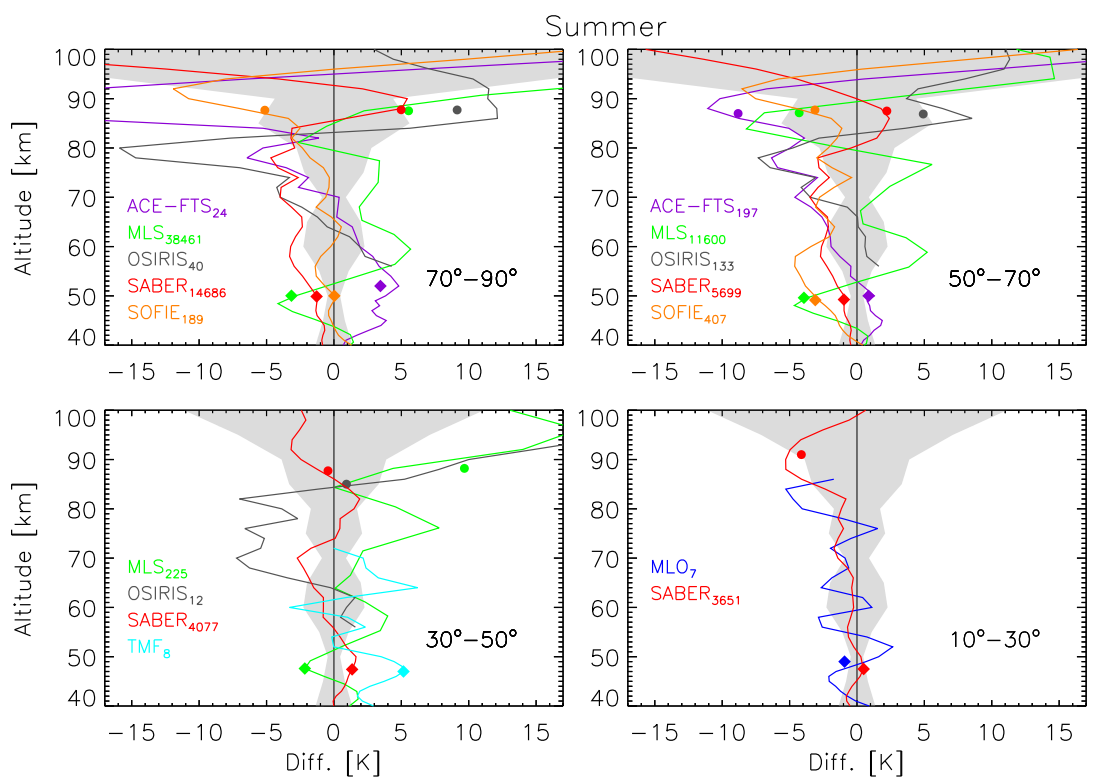

Figure 10. As in Fig. 6 but for summer (July for NH and January for SH) colocations in the NLC mode.

and 9), and also in the UA mode, particularly in its vertical shape. The magnitude of temperature differences at all altitudes is generally similar in all modes at all latitudes and seasons, except at the mesopause and at all altitudes at $50-70^{\circ}$ in the summer. Note also that the comparisons with ACE-FTS in the winter around the stratopause and with OSIRIS in the summer around $80 \mathrm{~km}$ exhibit larger (in absolute value) differences in the NLC-mode comparisons. All MIPAS-NLC and ACE-FTS colocations during the polar winter occurred only over the South Pole during JJA 2005 (27 coincidences). ACE-FTS temperatures around the stratopause are then lower than the other instruments' measurements. Comparisons with MIPAS-UA for the same period and latitudes also present the same behavior (there are then no MIPAS-MA colocations). Those larger differences do not show up in comparisons for other years. OSIRIS temperatures around $80 \mathrm{~km}$ are larger than the other instruments' measurements when close to the solstices (when NLC measurements take place), when the temperature vertical gradients are largest.

The NLC temperatures in the summer $50-70^{\circ}$ comparisons seem to be affected by biases similar (although slightly smaller) to those found in the $70-90^{\circ} \mathrm{MA}$ (and UA) full summer season temperature comparisons. Therefore, the same conclusions described in the previous section apply. That happens because the NLC measurements are taken very close to the solstices (and so are the colocations found), when the atmospheric conditions at $50-70^{\circ}$ are more extreme, which generally translates into larger differences with the other instruments. In other words, the MA and UA temperatures at $50-70^{\circ}$ also have larger differences with the other instruments close to the solstices than on average from the early to the late summer.
MIPAS NLC summer mesopause temperature comparisons with SABER, OSIRIS and MLS improve with respect to those of the MA and UA modes by around $2 \mathrm{~K}$ at $70-90^{\circ}$ latitudes. The better vertical resolution of the NLC temperatures does not explain that improvement because the modecharacteristic vertical resolution is accounted for when applying the averaging kernels. Different atmospheric conditions, like a more extreme temperature profile, are not the cause either. Indeed, when restricting the MA colocations to measurements taken on the closest days before and after NLC measurements, similar $2 \mathrm{~K}$ mesopause differences are found (see example of summer solstice comparisons with SABER in Fig. 12 at $70-90^{\circ}$ latitudes, where differences at $88 \mathrm{~km}$ are $7 \mathrm{~K}$ in the MA mode and $5 \mathrm{~K}$ in the NLC mode). Therefore, the most likely cause is the narrower vertical sampling performed in this mode $(1.5 \mathrm{~km}$ instead of $3 \mathrm{~km}$ in MA and UA), which, concomitant with the MIPAS $3 \mathrm{~km}$ field of view, is able to provide a less biased measurement in the coldest point in the region in v721. This might be explained by the nonlinearity effects, for example, in non-LTE radiative transfer.

\section{Differences in temperature interhemispheric asymmetries}

The understanding of atmospheric variable interhemispheric differences, commonly known as interhemispheric asymmetries, is an important topic that is currently often addressed in atmospheric studies. Studies based on differences are usually more reliable than those dealing with absolute values because the persistent (in time and/or place) systematic errors may cancel out. That is not the case if artificial spatial 

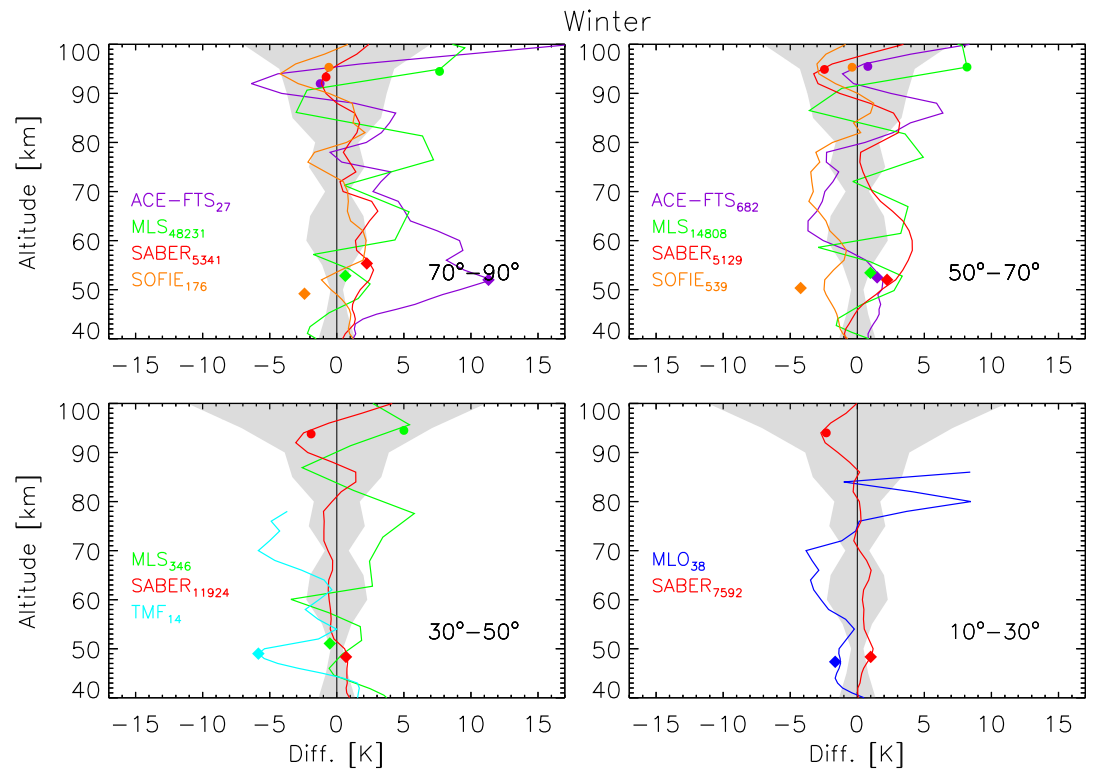

Figure 11. As in Fig. 6 but for winter (January for NH and July for SH) colocations in the NLC mode.

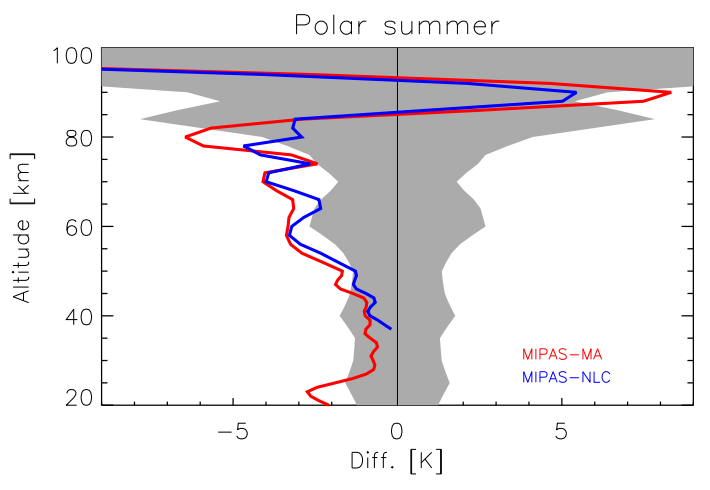

Figure 12. Average MIPAS NLC (blue) and MA (red) differences with SABER colocated measurements from 2008 to 2011 at $70-90^{\circ}$ latitudes. NLC average include coincidences found in the three days of NLC measurements. MA average include colocations found in the MA measurements taken on the closest day after and the closest day before the NLC measurements.

and temporal inhomogeneities in the measured atmospheric variables (which may be due to several aspects such as dependence of the retrievals on atmospheric conditions, dependence of the observations and/or inversions on the time or location, etc.) are present. A correct interpretation of interhemispheric asymmetries relies on the ability of the measurements to homogeneously reproduce the atmospheric state fields. Temperature interhemispheric asymmetries are widely used, for example, in polar mesospheric cloud studies (Winkler et al., 2012), for which a differential behavior in the two hemispheres occurs.
Our goal here is to assess MIPAS's ability to measure temperature and altitude interhemispheric asymmetries, or, in other words, detect differences between $\mathrm{NH}$ and $\mathrm{SH}$ measurements not originated by the real atmospheric state. Note that the difference between instruments in hemispheric asymmetry of certain observable is equivalent to the hemispheric asymmetry in the observable difference between instruments. That is, the resulting differences in temperature interhemispheric asymmetry also reflect deviations between $\mathrm{NH}$ and SH MIPAS temperature differences with the other instruments.

We compare the temperature and altitude interhemispheric asymmetries measured by MIPAS in the stratopause and the mesopause with those from the other five satellites. In order to avoid sampling effects (in location and/or time) as much as possible, we determined the interhemispheric asymmetries for each instrument from the set of colocated measurements. We also used the full season colocation set instead of selected periods, which assures a large number of colocations for all instruments in each hemisphere (plus a North and South Pole coverage by SABER, which alternates their observation every 2 months) and thus a representative result. Nevertheless, it is important to note that this approach implies that the absolute interhemispheric asymmetries derived using only the colocation sets (written below for the case of MIPAS) instead of each instrument complete data set do not coincide necessarily with the mean seasonal interhemispheric asymmetries measured by each of those instruments. This is precisely due to the limitation imposed by the different temporal and spatial distributions of the colocations along a season and a latitude box for each instrument pair. 

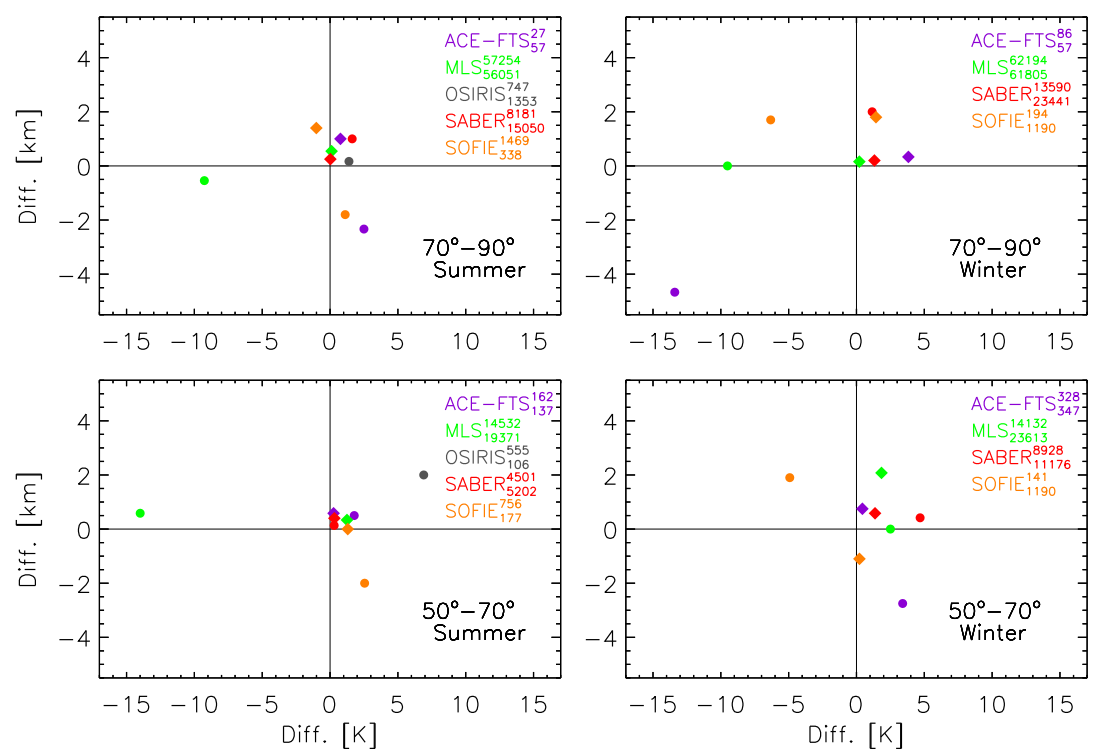

Figure 13. Difference (in absolute value) between stratopause (diamonds) and mesopause (circles) interhemispheric temperature ( $x$ axis) and altitude ( $y$ axis) anomalies (NH-SH) measured by MIPAS and the satellite instruments indicated for summer (left) and winter (right) at $70-90^{\circ}$ (top) and $50-70^{\circ}$ (bottom) latitudes. A positive sign of the difference indicates that the $\mathrm{NH}-\mathrm{SH}$ difference has the same sign in both instruments (and vice versa). The number of MIPAS coincidences with each instrument in the Northern and Southern Hemispheres are shown in the superscripts and subscripts, respectively.

Figure 13 shows the difference between MIPAS average $\mathrm{NH}-\mathrm{SH}$ asymmetries and those from colocated measurements from the other instruments in the stratopause and the mesopause, for the summer and winter seasons and at 70-90 and $50-70^{\circ}$ latitudes. The $x$ axes show the differences between instruments in the temperature asymmetry and the $y$ axes show the differences between instruments in the altitude asymmetry. In those plots we represent the absolute values of the asymmetry differences and assign a negative sign only when MIPAS asymmetry has the opposite sign to that from the other instrument (that is, if MIPAS measured a higher temperature in one hemisphere but the other instrument measured it in the other hemisphere). In other words, a positive/negative value indicates an agreement/disagreement in the sign of the asymmetry.

During summer, MIPAS stratopause temperature and altitude NH-SH asymmetries averaged for all colocation sets are $-3 \pm 2 \mathrm{~K}$ and $0 \pm 0.3 \mathrm{~km}$, respectively, for $70-90^{\circ}$, and $-4 \pm 1 \mathrm{~K}$ and $0 \pm 0.5 \mathrm{~km}$, respectively, for $50-70^{\circ}$. The differences between MIPAS and the other instruments summer stratopause temperature $\mathrm{NH}-\mathrm{SH}$ asymmetry are smaller than $1 \mathrm{~K}$ for both latitude boxes. It is worth noting that, in several cases, that value is significantly smaller than the corresponding absolute difference between the stratopause temperature measured by each instrument, as shown in Fig. 8 . The difference in the MIPAS summer stratopause altitude $\mathrm{NH}-\mathrm{SH}$ asymmetry from the other instruments is smaller than $1.5 \mathrm{~km}$ and within MIPAS vertical resolution at the corresponding altitude. MIPAS winter stratopause temperature and altitude $\mathrm{NH}-\mathrm{SH}$ asymmetries averaged for all colocation sets are $-16 \pm 5 \mathrm{~K}$ and $1 \pm 2 \mathrm{~km}$, respectively, for $70-90^{\circ}$, and $-6 \pm 3 \mathrm{~K}$ and $-2 \pm 2 \mathrm{~km}$, respectively, for $50-70^{\circ}$ (note that long periods after $\mathrm{NH}$ sudden stratospheric warnings, when the stratopause temperature significantly decreases, are included). MIPAS comparisons with MLS, SABER and SOFIE for winter stratopause temperature and altitude interhemispheric asymmetries are very good (smaller than $1 \mathrm{~K}$ and $2 \mathrm{~km}$, respectively) both at $70-90^{\circ}$ and $50-70^{\circ}$ latitudes, but there is a $4 \mathrm{~K}$ deviation with respect to the asymmetry measured by ACE-FTS at 70-90 . All instruments detect the same sign for the stratopause temperature hemispheric differences.

MIPAS summer mesopause temperature and altitude $\mathrm{NH}-\mathrm{SH}$ asymmetries averaged for all colocation sets are $-9 \pm 4 \mathrm{~K}$ and $0.5 \pm 1 \mathrm{~km}$, respectively, for $70-90^{\circ}$, and $-6 \pm 7 \mathrm{~K}$ and $-0.5 \pm 1 \mathrm{~km}$, respectively, for $50-70^{\circ}$. We note that a large standard deviation does not denote a large error of the anomaly measured by MIPAS but a wide spread due to the different periods in a season and/or locations in a latitude box of each set of MIPAS colocations with each instrument. Differences between MIPAS summer mesopause temperature and altitude $\mathrm{NH}-\mathrm{SH}$ asymmetries and the corresponding asymmetries measured by the other instruments are smaller than $2 \mathrm{~K}$ and $2 \mathrm{~km}$, respectively, except for the comparison with OSIRIS at $50-70^{\circ}$ and MLS. That $2 \mathrm{~K}$ temperature asymmetry difference is significantly smaller than the corresponding temperature absolute difference between the instruments at the mesopause (see Fig. 8). MLS exhibits a 
persistent deviation in its temperature hemispheric asymmetry of $10 \mathrm{~K}\left(70-90^{\circ}\right)$ and $15 \mathrm{~K}\left(50-70^{\circ}\right)$. The negative sign shown in the plot additionally indicates that MLS temperature interhemispheric asymmetry has a different sign from those of all other instruments (in particular, MLS NH summer mesopause is warmer than in the $\mathrm{SH}$, opposite to the behavior measured by the other instruments). OSIRIS temperature $\mathrm{NH}-\mathrm{SH}$ asymmetry difference from the other instruments is also large $(7 \mathrm{~K})$ at $50-70^{\circ}$ latitudes, but has the same sign.

MIPAS winter mesopause temperature and altitude $\mathrm{NH}-\mathrm{SH}$ asymmetries averaged for all colocation sets are $5 \pm 5 \mathrm{~K}$ and $1 \pm 0.4 \mathrm{~km}$, respectively, for $70-90^{\circ}$, and $8 \pm 4 \mathrm{~K}$ and $1 \pm 1 \mathrm{~km}$, respectively, for $50-70^{\circ}$. The comparisons of interhemispheric asymmetries in the winter mesopause are more variable. MIPAS NH-SH temperature asymmetry difference with SABER at $70-90^{\circ}$ is only $1 \mathrm{~K}$, and both instruments show the same sign. MIPAS and SABER winter temperature asymmetries at these latitudes are reversed with respect to the other instruments (see negative sign in Fig. 13). MIPAS temperature asymmetry differences are $7 \mathrm{~K}$ (SOFIE), $10 \mathrm{~K}$ (MLS) and $13 \mathrm{~K}$ (ACE-FTS); note that these values coincide with the hemispheric asymmetries in MIPAS temperature differences with those instruments. The winter comparisons improve in general at $50-70^{\circ}$, where MIPAS temperature asymmetry has the same sign as ACE-FTS, MLS and SABER and is $2-4 \mathrm{~K}$ larger. The temperature asymmetries they all measure there have opposite sign to that measured by SOFIE. MIPAS and SOFIE temperature asymmetry difference is $5 \mathrm{~K}$. The MIPAS altitude $\mathrm{NH}-\mathrm{SH}$ asymmetry in winter is within $2 \mathrm{~km}$ of those measured by the other instruments except ACE-FTS (4 km and different sign).

\section{Summary}

We present vM21 MIPAS temperatures, the latest version of temperatures retrieved in the $20-102 \mathrm{~km}$ altitude range from the MA, UA and NLC modes, which measured the carbon dioxide emissions in the $15 \mu \mathrm{m}$ region from January 2005 to April 2012. This version introduces the following updates with respect to the previous vM11: the HITRAN 2008 spectroscopic database; a climatology of atomic oxygen and carbon dioxide from WACCM-SD; a version of ESA-calibrated L1b spectra (5.02/5.06); and improvement in technical aspects of the retrieval setup, such as temperature gradient along the line-of-sight regularization, offset regularization, apodization accuracy, a priori, correction of $\mathrm{CO}_{2}$ non-LTE populations along the line of sight, $\mathrm{H}_{2} \mathrm{O}$ and $\mathrm{O}_{3}$ joint fit, and field-of-view radiance calculations.

The vM21 temperature, as compared to vM11, increases, on average, by $1-2 \mathrm{~K}$ in the stratopause and $0-2 \mathrm{~K}$ around $75 \mathrm{~km}$, mainly due to effects from the version of the spectroscopic database and L1b spectra, although effects from changes in the offset and temperature horizontal gradient regularizations at all latitudes, and also those in the apodization accuracy and the a priori in the polar summer, are not negligible.

Except for the summer high latitudes, vM21 temperatures from 80 to $100 \mathrm{~km}$ are smaller than in vM11, with a maximum $15 \mathrm{~K}$ decrease at the mesopause, mainly due to the $\mathrm{L} 1 \mathrm{~b}$ spectra version, and with smaller effects caused by (in this order) the upgraded temperature horizontal gradient regularization, the atomic oxygen abundance, the offset regularization, the apodization accuracy and the carbon dioxide concentration. In the summer high latitudes, the mesopause is 2-4 K warmer than in vM11, primarily due to the atomic oxygen but partially compensated for by the effect of the improved offset and temperature horizontal gradient regularizations. Temperature at $90 \mathrm{~km}$ decreases by $4 \mathrm{~K}$ due to the spectra version, the temperature horizontal gradient and offset regularizations, and the $\mathrm{CO}_{2}$ abundance. Although the causes for the temperature changes above $95 \mathrm{~km}$ are the same as at other latitudes, their effects are amplified in the polar summer and temperature decreases by up to $20 \mathrm{~K}$ at $100 \mathrm{~km}$.

The vM21 changes in temperature correct the main biases found from the lower stratosphere to the lower thermosphere in the comparisons of the previous temperatures (vM11) with other instruments, except around the mesopause during the high-latitude summers. Indeed, comparisons of the vM21 temperatures with measurements from ACE-FTS, MLS, OSIRIS, SABER, SOFIE and the two Rayleigh lidars at Mauna Loa and Table Mountain show, in general, significantly smaller differences (note that new versions are also used for ACE-FTS, MLS and SABER).

The MLO and TMF lidar measurements and MIPAS vM21 temperatures are generally within $1 \mathrm{~K}$ below $60 \mathrm{~km}$ and within $2-3 \mathrm{~K}$ from 60 to $80 \mathrm{~km}$. Systematic exceptions occur in the winters around $45 \mathrm{~km}$ in the comparisons over TMF, where MIPAS temperatures are $3 \mathrm{~K}$ lower; in both equinoxes around $70 \mathrm{~km}$ over MLO, where MIPAS temperatures are $4 \mathrm{~K}$ lower; and in the summers above $70 \mathrm{~km}$ over MLO and around $80 \mathrm{~km}$ over TMF, where MIPAS temperatures are up to $4-5 \mathrm{~K}$ lower and higher, respectively.

MIPAS and ACE-FTS comparisons are very good, except in the summer. Their temperatures are within $1-2 \mathrm{~K}$ below $80 \mathrm{~km}$ and $2-4 \mathrm{~K}$ above $80 \mathrm{~km}$ in spring, autumn and winter (except for a narrow region around $80 \mathrm{~km}$ in the spring at $50-70^{\circ}$ ). In the summer, MIPAS (and the rest of the instruments) on average measures a $3 \mathrm{~K}(5 \mathrm{~K})$ warmer stratopause and a more than $15 \mathrm{~K}(20 \mathrm{~K})$ colder mesopause.

The comparisons with MLS are good in the stratosphere, but MLS exhibits a colder upper stratosphere and lower temperatures than MIPAS (and the other instruments) at $55-75 \mathrm{~km}(0-5 \mathrm{~K})$ and at the mesopause (3-10 K). MLS also differs from the other instruments in the temperature interhemispheric asymmetry because, in contrast to them, it measures a (significantly) colder summer mesopause in the Southern Hemisphere. 
The differences between MIPAS and OSIRIS below $85 \mathrm{~km}$ are smaller than $2 \mathrm{~K}$ in spring, and $4 \mathrm{~K}$ in autumn and summer, with MIPAS temperatures being colder. Differences at $85-90 \mathrm{~km}$ are generally larger and reach $10 \mathrm{~K}$ in the summer high latitudes (mesopause) or $7 \mathrm{~K}$ (right below the mesopause) in other conditions. The difference at $95 \mathrm{~km}$ is reduced to $2-4 \mathrm{~K}$.

Comparisons with SABER are remarkably good, bringing differences smaller than $2 \mathrm{~K}$ at all altitudes and seasons, except for high-latitude summers above $65 \mathrm{~km}$. That means that average MIPAS-SABER differences between previous versions have been eliminated or significantly reduced in most conditions. The only exception occurs during the polar summer, when they are $3-4 \mathrm{~K}$ at $65-80 \mathrm{~km}$ (MIPAS colder) and $5-7 \mathrm{~K}$ around the mesopause (MIPAS warmer).

MIPAS and SOFIE differences are smaller than $2 \mathrm{~K}$ in the stratosphere. SOFIE stratopause is generally $3 \mathrm{~K}$ colder than MIPAS and, in general, the other instruments. Their temperatures in the mesosphere are within 1-3 K, MIPAS being generally colder. Except for autumn, MIPAS mesopause is 3-5 K colder than SOFIE.

Overall, MIPAS vM21 temperature comparisons exhibit typical (with a few specific exceptions) differences smaller than $1 \mathrm{~K}$ below $50 \mathrm{~km}$ and smaller than $2 \mathrm{~K}$ at $50-80 \mathrm{~km}$ in spring, autumn and winter at all latitudes, and summer at low to midlatitudes. Differences between MIPAS and the other instruments in the summer high latitudes are typically smaller than $1 \mathrm{~K}$ below $50 \mathrm{~km}$, smaller than $2 \mathrm{~K}$ at $50-65 \mathrm{~km}$ and $5 \mathrm{~K}$ at $65-80 \mathrm{~km}$. The differences in the mid-mesosphere are generally negative. MIPAS mesopause temperature lies within the range of the other measurements. It is generally within $4 \mathrm{~K}$, except in the high-latitude summers, when it is within $10 \mathrm{~K}$. The polar summer comparisons with SABER, MLS and OSIRIS point to a too warm MIPAS mesopause, whereas those with ACE-FTS and SOFIE to a too cold mesopause. The agreement in the lower thermosphere is typically better than $5 \mathrm{~K}$, except for high latitudes during spring and summer, when MIPAS usually exhibits larger vertical gradients.

Despite sometimes larger differences between the temperatures measured by each instrument that sometimes exist, the comparisons of the interhemispheric temperature anomalies determined from the colocated observations indicate that MIPAS provides summer and winter stratopause and summer mesopause anomalies generally within $2 \mathrm{~K}$ of the other instrument measurements. The winter mesopause anomaly is generally within $4-5 \mathrm{~K}$. This is not the case for the mesopause temperature anomaly comparison with MLS during summer and polar winter, SOFIE during the winter, and ACE-FTS in the polar winter, which even observe anomalies of opposite sign.

The Supplement related to this article is available online at doi:10.5194/amt-7-3633-2014-supplement.
Acknowledgements. M. García-Comas was financially supported by the Ministry of Economy and Competitiveness (MINECO) through its "Ramón y Cajal" subprogram. The IAA team was supported by the Spanish MINECO, through project AYA2011-23552, the CONSOLIDER program CSD2009-00038, and EC FEDER funds. Funding for ACE comes primarily from the Canadian Space Agency. We thank ESA for providing MIPAS level-1b data.

Edited by: M. Rapp

\section{References}

Boone, C. D., Walker, K. A., and Bernath, P. F.: Version 3 retrievals for the Atmospheric Chemistry Experiment Fourier Transform Spectrometer (ACE-FTS), in: The Atmospheric Chemistry Experiment ACE at 10: A Solar Occultation Anthology, edited by: Bernath, P. F., 103-127, A. Deepak Publishing, Hampton, Virginia, USA, 2013.

Fischer, H., Birk, M., Blom, C., Carli, B., Carlotti, M., von Clarmann, T., Delbouille, L., Dudhia, A., Ehhalt, D., Endemann, M., Flaud, J. M., Gessner, R., Kleinert, A., Koopman, R., Langen, J., López-Puertas, M., Mosner, P., Nett, H., Oelhaf, H., Perron, G., Remedios, J., Ridolfi, M., Stiller, G., and Zander, R.: MIPAS: an instrument for atmospheric and climate research, Atmos. Chem. Phys., 8, 2151-2188, doi:10.5194/acp-8-2151-2008, 2008.

Funke, B., López-Puertas, M., García-Comas, M., Kaufmann, M., Höpfner, M., and Stiller, G. P.: GRANADA: a Generic RAdiative traNsfer AnD non-LTE population Algorithm, J. Quant. Spectrosc. Ra., 113, 1771-1817, doi:10.1016/j.jqsrt.2012.05.001, 2012.

Garcia, R. R., Marsh, D. R., Kinnison, D. E., Boville, B. A., and Sassi, F.: Simulation of secular trends in the middle atmosphere, J. Geophys. Res., 112, D09301, doi:10.1029/2006JD007485, 2007.

García-Comas, M., López-Puertas, M., Marshall, B., Wintersteiner, P. P., Funke, B., Bermejo-Pantaléon, D., Mertens, C. J., Remsberg, E. E., Gordley, L. L., Mlynczak, M., and Russell, J.: Errors in SABER kinetic temperature caused by non-LTE model parameters, J. Geophys. Res., 113, D24106, doi:10.1029/2008JD010105, 2008.

García-Comas, M., Funke, B., López-Puertas, M., BermejoPantaleón, D., Glatthor, N., von Clarmann, T., Stiller, G., Grabowski, U., Boone, C. D., French, W. J. R., Leblanc, T., López-González, M. J., and Schwartz, M. J.: On the quality of MIPAS kinetic temperature in the middle atmosphere, Atmos. Chem. Phys., 12, 6009-6039, doi:10.5194/acp-12-6009-2012, 2012.

Kaufmann, M., Zhu, Y., Ern, M., and Riese, M.: Global distribution of atomic oxygen in the mesopause region as derived from SCIAMACHY O $\left({ }^{1} \mathrm{~S}\right)$ green line measurements, Geophys. Res. Lett., 41, 6274-6280, doi:10.1002/2014GL060574, 2014.

Kiefer, M., Arnone, E., Dudhia, A., Carlotti, M., Castelli, E., von Clarmann, T., Dinelli, B. M., Kleinert, A., Linden, A., Milz, M., Papandrea, E., and Stiller, G.: Impact of temperature field inhomogeneities on the retrieval of atmospheric species from MIPAS IR limb emission spectra, Atmos. Meas. Tech., 3, 1487-1507, doi:10.5194/amt-3-1487-2010, 2010.

Lamarque, J.-F., Emmons, L. K., Hess, P. G., Kinnison, D. E., Tilmes, S., Vitt, F., Heald, C. L., Holland, E. A., Lauritzen, 
P. H., Neu, J., Orlando, J. J., Rasch, P. J., and Tyndall, G. K.: CAM-chem: description and evaluation of interactive atmospheric chemistry in the Community Earth System Model, Geosci. Model Dev., 5, 369-411, doi:10.5194/gmd-5-369-2012, 2012

Leblanc, T., McDermid, I. S., Hauchecorne, A., and Keckhut, P.: Evaluation of optimization of lidar temperature analysis algorithms using simulated data, J. Geophys. Res., 103, 6177-6188, doi:10.1029/97JD03494, 1998.

Leblanc, T., McDermid, I. S., Keckhut, P., Hauchecorne, A., She, C. Y., and Krueger, D. A.: Temperature climatology of the middle atmosphere from long-term lidar measurements at middle and low latitudes, J. Geophys. Res., 103, 17,191-17,204, 1998a.

López-Puertas, M. and Taylor, F. W.: Non-LTE radiative transfer in the Atmosphere, World Scientific Pub., Singapore, 2001.

López-Puertas, M., García-Comas, M., Funke, B., BermejoPantaleón, D., Höpfner, M., Grabowski, U., Stiller, G. P., von Clarmann, T., and von Savigny, C.: Measurements of polar mesospheric clouds in infrared emission by MIPAS/ENVISAT, J. Geophys. Res., 114, D00I07, doi:10.1029/2009JD012548, 2009.

Marshall, B. T., Deaver, L. E., Thompson, R. E., Gordley, L. L., McHugh, M. J., Hervig, M. E., and Russell III, J. M.: Retrieval of temperature and pressure using broadband solar occultation: SOFIE approach and results, Atmos. Meas. Tech., 4, 893-907, doi:10.5194/amt-4-893-2011, 2011.

Mlynczak, M. G., Hunt, L. A., Mast, J. C., Thomas Marshall, B., Russell, J. M., Smith, A. K., Siskind, D. E., Yee, J.-H., Mertens, C. J., Martin-Torres, F. J., Thompson, R. E., Drob, D. P., and Gordley, L. L.: Atomic oxygen in the mesosphere and lower thermosphere derived from SABER: Algorithm theoretical basis and measurement uncertainty, J. Geophys. Res., 118, 5724-5735, doi:10.1002/jgrd.50401, 2013.

Oelhaf, H.: MIPAS Mission Plan, ESA Technical Note ENVISPPA-EOPG-TN-07-0073, 2008.

Picone, J., Hedin, A., Drob, D., and Aikin, A.: NRLMSISE00 empirical model of the atmosphere: Statistical comparisons and scientific issues, J. Geophys. Res., 107, 1468, doi:10.1029/2002JA009430, 2002

Raspollini, P., Carli, B., Ceccherini, S., Forzieri, G., Sgheri, L., Ridolfi, M., Carlotti, M., Papandrea, E., Arnone, E., Dinelli, B. M., Castelli, E., Remedios, J., Sembhi, H., Dudhia, A., Lopez-Puertas, M., Funke, B., Flaud, J.-M., von Clarmann, T., Hoepfner, M., Oelhaf, H., Fischer, H., Kiefer, M., Kleinert, A., Chipperfield, M., Perron, G., Aubertin, G., Birk, M., Wagner, G., Gessner, R., Mosner, P., Schmitt, M., Fehr, T., D’Alba, L., and Niro, F.: Eight years of MIPAS measurements, in: Proc. ESA Living Planet Symposium, Vol. SP-686, ESA Publication Division, 2010 .

Remsberg, E. E., Marshall, B. T., García-Comas, M., Krueger, D., Lingenfelser, G. S., Martin-Torres, J., Mlynczak, M. G., Russell, J. M., I., Smith, A. K., Zhao, Y., Brown, C., Gordley, L. L., López-Gonzalez, M. J., López-Puertas, M., She, C.-Y., Taylor, M. J., and Thompson, R. E.: Assessment of the quality of the Version 1.07 temperature-versus-pressure profiles of the middle atmosphere from TIMED/SABER, J. Geophys. Res., 113, D17101, doi:10.1029/2008JD010013, 2008.

Rothman, L. S., Gordon, I. E., Barbe, A., Benner, D. C., Bernath, P. F., Birk, M., Boudon, V., Brown, L. R., Campargue, A., Champion, J., Chance, K., Coudert, L. H., Dana, V., Devi, V. M., Fally,
S., Flaud, J., Gamache, R. R., Goldman, A., Jacquemart, D., Kleiner, I., Lacome, N., Lafferty, W. J., Mandin, J., Massie, S. T., Mikhailenko, S. N., Miller, C. E., Moazzen-Ahmadi, N., Naumenko, O. V., Nikitin, A. V., Orphal, J., Perevalov, V. I., Perrin, A., Predoi-Cross, A., Rinsland, C. P., Rotger, M., Šimečková, M., Smith, M. A. H., Sung, K., Tashkun, S. A., Tennyson, J., Toth, R. A., Vandaele, A. C., and Vander Auwera, J.: The HITRAN 2008 molecular spectroscopic database, J. Quant. Spectrosc. Ra., 110, 533-572, doi:10.1016/j.jqsrt.2009.02.013, 2009.

Schwartz, M. J., Waliser, D. E., Tian, B., Wu, D. L., Jiang, J. H., and Read, W. G.: Characterization of MJO-related upper tropospheric hydrological processes using MLS, Geophys. Res. Lett., 35, L08812, doi:10.1029/2008GL033675, 2008.

Sheese, P. E., Strong, K., Llewellyn, E. J., Gattinger, R. L., Russell III, J. M., Boone, C. D., Hervig, M. E., Sica, R. J., and Bandoro, J.: Assessment of the quality of OSIRIS mesospheric temperatures using satellite and ground-based measurements, Atmos. Meas. Tech., 5, 2993-3006, doi:10.5194/amt-5-2993-2012, 2012.

Sica, R. J., Izawa, M. R. M., Walker, K. A., Boone, C., Petelina, S. V., Argall, P. S., Bernath, P., Burns, G. B., Catoire, V., Collins, R. L., Daffer, W. H., De Clercq, C., Fan, Z. Y., Firanski, B. J., French, W. J. R., Gerard, P., Gerding, M., Granville, J., Innis, J. L., Keckhut, P., Kerzenmacher, T., Klekociuk, A. R., Kyrö, E., Lambert, J. C., Llewellyn, E. J., Manney, G. L., McDermid, I. S., Mizutani, K., Murayama, Y., Piccolo, C., Raspollini, P., Ridolfi, M., Robert, C., Steinbrecht, W., Strawbridge, K. B., Strong, K., Stübi, R., and Thurairajah, B.: Validation of the Atmospheric Chemistry Experiment (ACE) version 2.2 temperature using ground-based and space-borne measurements, Atmos Chem. Phys., 8, 35-62, doi:10.5194/acp-8-35-2008, 2008.

Stevens, M. H., Deaver, L. E., Hervig, M. E., Russell III, J. M., Siskind, D. E., Sheese, P. E., Llewellyn, E. J., Gattinger, R. L., Höffner, J., and Marshall, B. T.: Validation of upper mesospheric and lower thermospheric temperatures measured by the Solar Occultation for Ice Experiment, J. Geophys. Res.-Atmos., 117, D16304, doi:10.1029/2012JD017689, 2012.

von Clarmann, T., Glatthor, N., Grabowski, U., Höpfner, M., Kellmann, S., Kiefer, M., Linden, A., Mengistu Tsidu, G., Milz, M., Steck, T., Stiller, G. P., Wang, D. Y., Fischer, H., Funke, B., Gil-López, S., and López-Puertas, M.: Retrieval of temperature and tangent altitude pointing from limb emission spectra recorded from space by the Michelson Interferometer for Passive Atmospheric Sounding (MIPAS), J. Geophys. Res., 108, 4736, doi:10.1029/2003JD003602, 2003.

von Clarmann, T., Höpfner, M., Kellmann, S., Linden, A., Chauhan, S., Funke, B., Grabowski, U., Glatthor, N., Kiefer, M., Schieferdecker, T., Stiller, G. P., and Versick, S.: Retrieval of temperature, $\mathrm{H}_{2} \mathrm{O}, \mathrm{O}_{3}, \mathrm{HNO}_{3}, \mathrm{CH}_{4}, \mathrm{~N}_{2} \mathrm{O}, \mathrm{ClONO}_{2}$ and $\mathrm{ClO}$ from MIPAS reduced resolution nominal mode limb emission measurements, Atmos. Meas. Tech., 2, 159-175, doi:10.5194/amt-2-159-2009, 2009.

Winkler, H., von Savigny, C., Burrows, J. P., Wissing, J. M., Schwartz, M. J., Lambert, A., and García-Comas, M.: Impacts of the January 2005 solar particle event on noctilucent clouds and water at the polar summer mesopause, Atmos. Chem. Phys., 12, 5633-5646, doi:10.5194/acp-12-5633-2012, 2012. 